\title{
WestVirginiaUniversity
}

THE RESEARCH REPOSITORY @ WVU

Graduate Theses, Dissertations, and Problem Reports

2010

\section{Three Essays on the Foreign Exchange and Equity Returns}

Alina F. Klein

West Virginia University

Follow this and additional works at: https://researchrepository.wvu.edu/etd

\section{Recommended Citation}

Klein, Alina F., "Three Essays on the Foreign Exchange and Equity Returns" (2010). Graduate Theses, Dissertations, and Problem Reports. 3156.

https://researchrepository.wvu.edu/etd/3156

This Dissertation is protected by copyright and/or related rights. It has been brought to you by the The Research Repository @ WVU with permission from the rights-holder(s). You are free to use this Dissertation in any way that is permitted by the copyright and related rights legislation that applies to your use. For other uses you must obtain permission from the rights-holder(s) directly, unless additional rights are indicated by a Creative Commons license in the record and/ or on the work itself. This Dissertation has been accepted for inclusion in WVU Graduate Theses, Dissertations, and Problem Reports collection by an authorized administrator of The Research Repository @ WVU.

For more information, please contact researchrepository@mail.wvu.edu. 


\title{
Three Essays on the Foreign Exchange and Equity Returns
}

\author{
Alina F. Klein \\ Dissertation submitted to the College of Business \& Economics \\ at West Virginia University \\ in partial fulfillment of the requirements \\ for the degree of \\ Doctor of Philosophy \\ in \\ Economics
}

Ronald J. Balvers, Ph.D., Committee Chairperson Arabinda Basistha, Ph.D.

Stratford Douglas, Ph.D.

Alex Kurov, Ph.D.

Costanza Meneghetti, Ph.D.

Department of Economics

Morgantown, West Virginia

2010

Keywords: Foreign Exchange; Trading Strategies; Asset Pricing; Risk Copyright 2010 Alina F. Klein 


\title{
ABSTRACT \\ Three Essays on the Foreign Exchange and Equity Returns
}

\begin{abstract}
Alina F. Klein
This dissertation contains three essays dealing with current issues in the foreign exchange and equity exchange markets. The first essay observes that both markets display behaviors akin to momentum and mean reversion. This essay implements a trading strategy combining mean reversion and momentum in foreign exchange markets. The strategy was originally designed for equity markets, but it also generates abnormal returns when applied to uncovered interest parity deviations for five countries. I find that the pattern for the positions thus created in the foreign exchange markets is qualitatively similar to that found in the equity markets. Quantitatively, this strategy performs better in foreign exchange markets than in equity markets. Also, it outperforms traditional foreign exchange trading strategies, such as carry trades and moving average rules.

In the second essay, we further examine the strategy combining mean reversion and momentum in the FX market. Our goal is to find it the abnormal returns thus obtained are compensation for risk. We find a striking similarity between the common stock and FX market returns. We analyze different asset pricing models through a variety of econometrical procedures, such as GMM and two-pass approach. When comparing these models, we assert that the Consumption CAPMs are the only ones that can explain the FX returns.

In the third essay, I look at the zero-investment uncovered interest parity (UIP) portfolio positions as perfect factor-mimicking portfolios for currency risk in the International CAPM context. Their returns are the currency risk premia. Since the UIP positions on average provide low returns, the currency risk premia must be low so that currency risk appears not to be priced in an unconditional model. However, previous research has shown that UIP returns are predictable and may be quite substantial conditionally. I use this observation to generate a specific conditional version of the International CAPM. A GMM approach shows that the conditional model performs well, while the unconditional International CAPM is marginal. The paper thus argues that previous rejections of the International CAPM stem from the fact that currency risk premia are by nature low over extended periods of time and do not provide evidence against the International CAPM.
\end{abstract}




\section{Dedication}

I dedicate this dissertation to my husband, Rudi, for his continuous love and support 


\section{Acknowledgments}

Many people helped me get where I am today and I would like to acknowledge some of them. Firstly, I am very grateful to my advisor, Ronald Balvers, for his guidance and continuous support. I thank him not only for the vast amount of knowledge he tried to bestow on me in class or in his office during my numerous announced and unannounced visits, but also for his optimism and patience. I am also thankful to the other members of my dissertation committee: Arabinda Basistha, Stratford Douglas, Alex Kurov and Costanza Meneghetti for their valuable suggestions.

Lillian Kamal and Richard Baillie are also gratefully acknowledged for their help in providing the data. I would also like to thank Yangru $\mathrm{Wu}$ for his help with the programming.

And for my parents who made me who I am today, a special thank you. My mother has always been there for me, trusted me and gave me her full support in any decision I made, even when that decision got me thousands of miles away from her. I would like to thank her for putting my happiness above hers. I am also grateful to my late father for raising me as he did, for inoculating in me his love for learning and for helping me achieve what he knew I could when I did not.

I am also thankful to two other members of my family who helped shape my personality: my aunt, Stanica, and my late grandmother. They were always there for me and I miss them dearly. I am also grateful to my second family, Nusa and Silvius Klein, without whom I definitely would not be here. Thank you for you advice and your moral and material support.

Finally, I would like to thank my husband, Rudi, to whom this dissertation is dedicated. Without him, I would not be here today. He taught me English and convinced me to try pursuing a doctorate degree. He was here with me the whole time, in sickness and in health, in the bad moments and in the happy ones. Thank you for helping me learn who I am and for making me a better person. 


\section{Multumiri}

\section{(Translation of acknowledgements in Romanian)}

Multi oameni m-au ajutat sa ajung unde sunt astazi si as vrea sa multumesc catorva dintre ei. In primul rand, ii sunt foarte recunoscatoare profesorului meu indrumator, Ronald Balvers, pentru ca m-a carmuit si a fost alaturi de mine in tot acest timp. Ii multumesc nu numai pentru cantitatea enorma de informatie pe care a incercat sa mi-o transmita in timpul orelor si in biroul lui in timpul numeroaselor mele vizite anuntate si neanuntate, dar si pentru optimismul si rabdarea lui. De asemenea as vrea sa le multumesc membrilor comisiei mele de dizertatie: Arabinda Basistha, Stratford Douglas, Alex Kurov si Costanza Meneghetti, pentru sugestiile lor valoroase.

Lillian Kamal si Richard Baillie sunt de asemenea mentionati cu recunostinta pentru ajutor in colectarea datelor. Ii multumesc si lui Yangru Wu pentru ajutorul lui in programare.

As dori sa multumesc in mod special parintilor mei, datorita carora sunt ceea ce sunt astazi. Mama mea a fost mereu alaturi de mine, a avut incredere in mine si $\mathrm{m}-\mathrm{a}$ sustinut in orice decizie am luat in viata, chiar daca una dintre aceste decizii m-a trimis la mii de kilometri departare de ea. As vrea sa-i multumesc pentru ca a pus mereu fericirea mea deasupra fericirii ei. Sunt recunoscatoare si tatalui meu, care nu mai e alaturi de noi. El m-a invatat sa iubesc sa invat si $\mathrm{m}$-a ajutat sa ating in viata obiective pe care el stia ca le pot atinge, chiar cand eu nu stiam asta.

Mai sunt doi membri ai familiei carora as vrea sa le multumesc, care au contribuit la formarea personalitatii mele: matusa mea, Stanica, si bunica mea plecata dintre noi. Ele m-au sustinut mereu si imi e dor de ele crunt. Sunt de asemenea recunoascatoare celei dea doua familii ale mele: Nusa si Silvius Klein, fara de care cu siguranta nu as fi aici. Multumesc pentru sfaturi si pentru ajutorul moral si material.

In sfarsit, vreau sa-i multumesc sotului meu, Rudi, caruia ii este dedicata aceasta lucrare. Fara el, nu as fi in aceasta ipostaza astazi. El m-a invatat limba engleza si m-a convins sa incerc sa obtin un doctorat. A fost alaturi de mine in tot acest timp, la bine si la rau. Multumesc pentru ca m-ai ajutat sa inteleg cine sunt si sa devin un om mai bun. 


\section{Table of Contents}

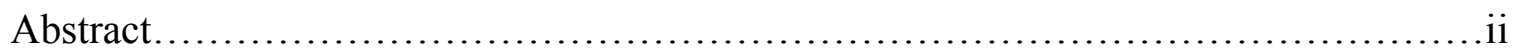

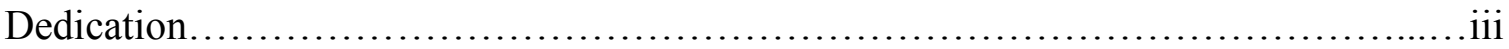

Acknowledgements................................................................

Multumiri (translation of acknowledgements in Romanian) ............................

Table of Contents....................................................................

List of Tables...........................................................................

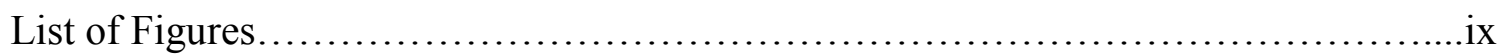

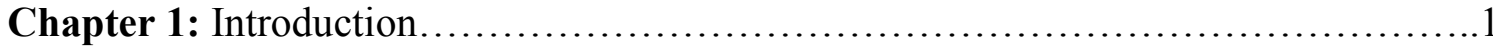

Chapter 2: Combining Mean Reversion and Momentum Strategies in Foreign Exchange

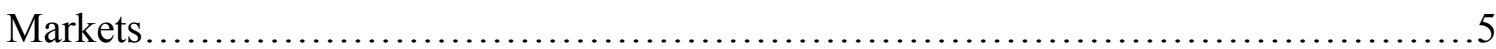

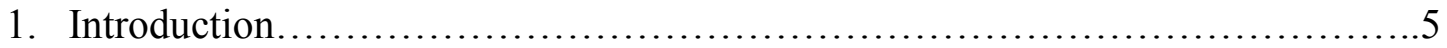

2. Data Description and Preliminary Statistics.................................. 7

2.1. Data Description.......................................................

2.2. Interest Parity Conditions............................................... 7

2.3. Confirming Mean Reversion and Momentum.............................9

3. Model and Parameter Estimation.............................................. 10

3.1. Model.............................................................. 10

3.2. Parameter Estimation..................................................... 12

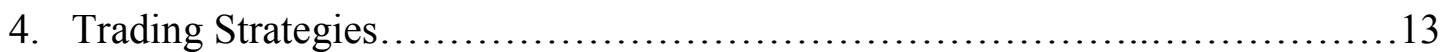

4.1. The Pure Mean Reversion Strategy ...................................15

4.2. The Pure Momentum Strategy...........................................15

4.3. The Combination Strategy................................................16

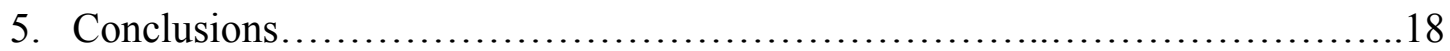

Chapter 3: Are FX Returns Compensation for Risk? (with Rudolf F. Klein) ...............26

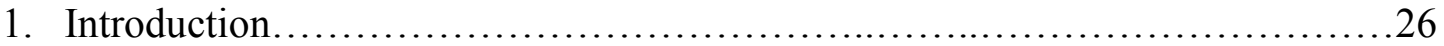

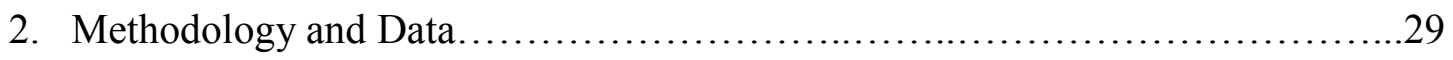

2.1. Combining Mean Reversion and Momentum Strategy.......................29

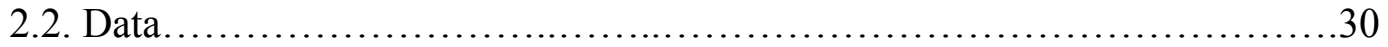

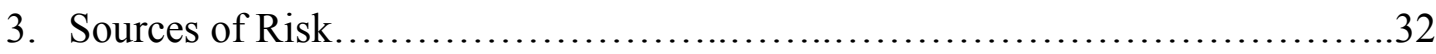

3.1. CAPM, International CAPM and APT ..................................... 
3.2. Monetary Explanations............................................... 38

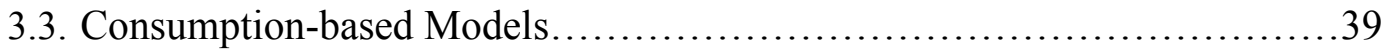

3.4. Model Comparison..................................................42

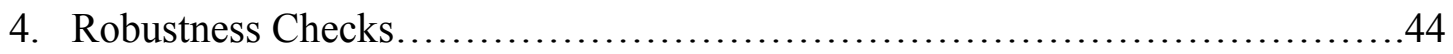

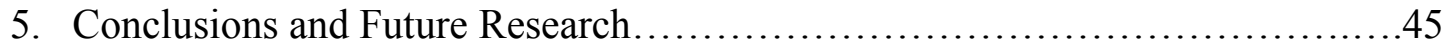

Chapter 4: Currency Risk Premia and Uncovered Interest Parity in the International

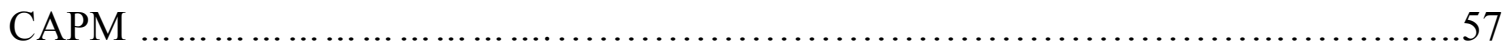

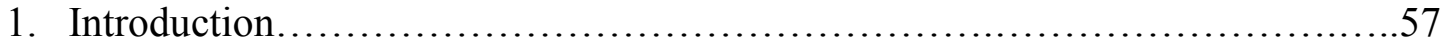

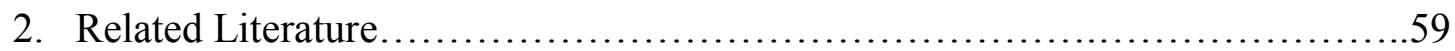

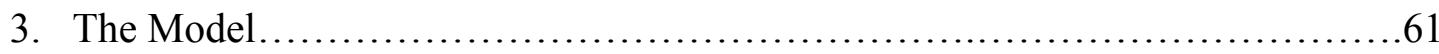

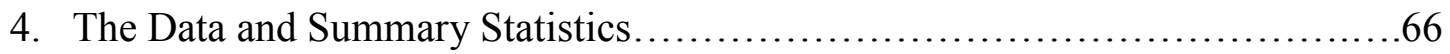

4.1. Data and the Currency Return Measures....................................66

4.2. Currency Returns and Risk Premia....................................67

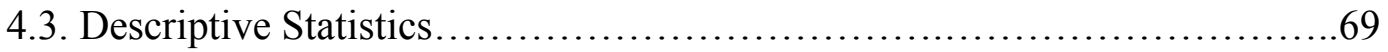

4.4. Two-Pass Approach....................................................69

5. GMM Estimation of the Conditional Model.......................................70

5.1. Estimation of the Classic and International CAPM's.......................71

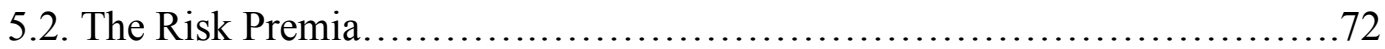

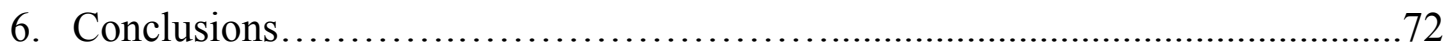

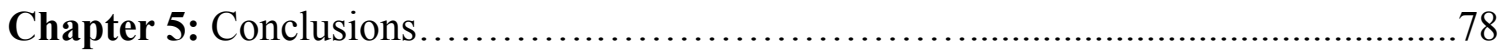

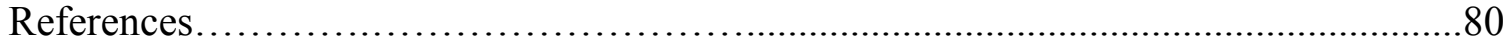

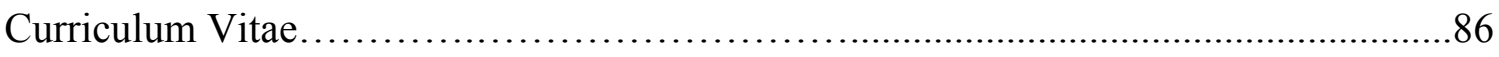




\section{List of Tables}

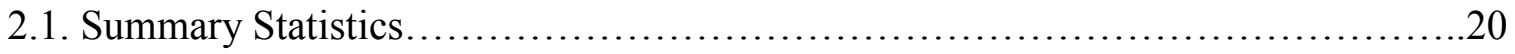

2.2. Model Parameters and Variance Decomposition..................................21

2.3. Performance of the Pure Mean Reversion Strategy and the Pure Momentum

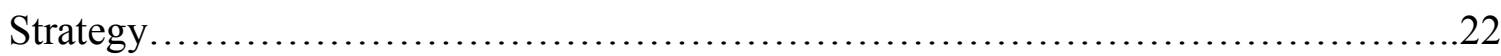

2.4. Performance of the Combination Strategy .....................................24

3.1. Descriptive Statistics...........................................................

3.2. Time Series Regressions........................................................ 48

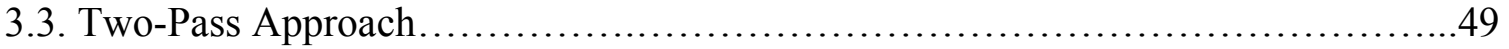

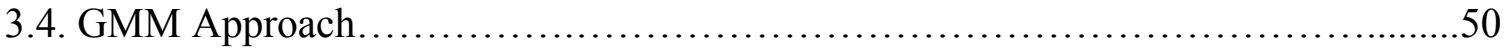

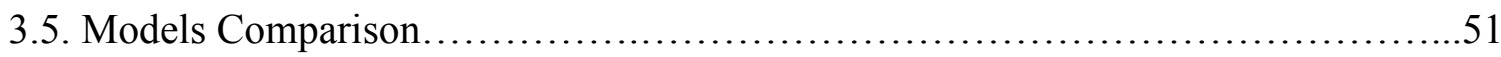

3.6. GMM First Stage - Sub-periods................................................. 52

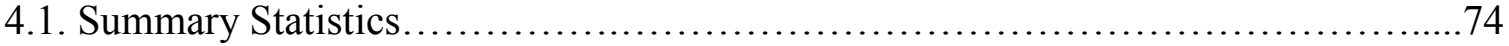

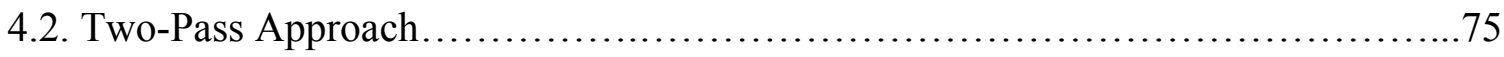

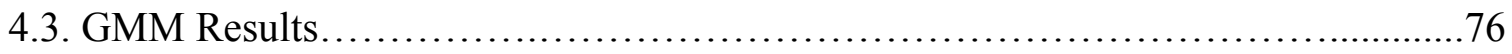

4.4. Estimated Risk Premia for the Conditional International CAPM..........................77 


\section{List of Figures}

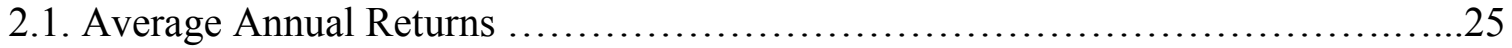

3.1. Durable and Nondurable Consumption...................................53

3.2. Mean Estimated Returns vs. Mean Realized Returns for the FX Portfolios Obtained through GMM First Stage Approach................................................... 3.3. Mean Estimated Returns vs. Mean Realized Returns for the FX Portfolios Obtained through GMM Second Stage Approach.........................................55 3.4. Mean Estimated Returns vs. Mean Realized Returns for the FX Portfolios and the 25

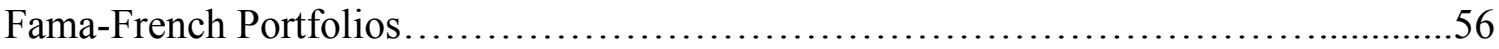




\section{Chapter 1: Introduction}

The FX market is one of the most active financial markets. Scholars tried to theoretically explain how this market functions. And yet, speculators manage to find profit opportunities.

One of the foundations of the FX literature, the Uncovered Interest Parity (UIP) states that one cannot expect to make profits by borrowing from a low-interest rate country and lending in a high-interest rate country, due to changes in the exchange rates. However, Fama (1984) uncovers that the forward exchange rates are actually biased estimators of the spot exchange rates and the UIP does not hold. A low-yielding currency in fact depreciates, thus creating profit opportunities. This finding is known as the "forward puzzle" and it is one of the most often investigated puzzles in the finance.

The literature on the UIP is divided into two branches. The first division uses the deviations from UIP to create different trading strategies, such as momentum strategies, mean reversion strategies, and carry trades. The second section studies the deviations from UIP as a proxy for currency risk premia and uses them in asset pricing models (i.e., International CAPM).

This dissertation takes a fresh approach on both aspects. The first essay (presented in Chapter 2) finds a combination of mean reversion and momentum strategy that creates profit opportunities. I analyze the deviations from UIP for five developed countries, among which the US is the home country. The essay constructs onto a strategy already employed in the literature, but in different market: the equity market. The main model was created by Fama and French (1988) and Summers (1986) to show that there exists mean reversion in the stock market. Balvers and $\mathrm{Wu}(2006)$ use this model to create a 
strategy that incorporates both mean reversion and momentum in the stock market. They find significant and positive returns for the portfolios thus created.

The FX literature on trading strategies usually uses mean reverting behavior toward PPP values and moving average rules to account for momentum effects. However, to the best of my knowledge, no other paper employs a strategy originally designed for the equity markets, to then construct returns similar to those existing in the equity markets (i.e., I use the deviations from UIP as returns on FX portfolios) and to find significant returns. My first essay is inventive due to the use of existing literature in a new context.

My results are in line with earlier findings that the stock and FX markets have similar behavior. I find Sharpe ratios that are positive and larger than in the equity markets. I conclude that the two markets are either inefficient, or the abnormal returns are compensation for a common source of risk.

The second essay (presented in Chapter 3) examines the cause of the mean reversion and momentum behaviors noticed in the FX market. This chapter is coauthored with Rudolf F. Klein. We test if the strategy created in the first essay becomes unproductive when accounting for risk.

Firstly, we review the literature on risk factors in the FX market. We use three econometrical approaches: time-series, two-pass and GMM. There are three main branches in the literature. The first one considers very well-known asset pricing models in the equity market, such as the CAPM and the APT. We do not find any of these models to perfectly explain the abnormal returns. The International CAPM and FamaFrench three factor model behave slightly better than the classic CAPM, in that we 
cannot reject their validity under the GMM approach. However, a graphic representation of the results shows that the estimated mean returns of the analyzed portfolios are not as close to the actual returns as they should be. Also: the $\mathrm{R}^{2}$ is negative.

The second source of risk investigated in the FX literature is the monetary explanation. It has been discussed that the "forward puzzle" exists due to Central Banks' interventions. There is no consensus on this issue in the literature. We do not find this to be a valid explanation for the positive returns obtained through the combination of mean reversion and momentum with any of the three employed econometrical procedures.

The third type of asset pricing model used in the FX literature is also the most controversial and deals with the CCAPM and its extension as proposed by Yogo (2006). Some studies show that when including the durables stock along with the nondurables consumption, returns on FX portfolios can be explained. This means that the investors get positive returns, but that is only because they are compensated for risk. These two models (and the extended version especially) are the best fitted models for our returns.

We also compare the analyzed asset pricing models based on Lewellen et al. (2010) and conclude again that the consumption based models can explain relatively well the positive and significant returns obtained on the FX market.

The third essay (presented in Chapter 4) considers the issue of the UIP deviations being measures of currency risk premia. The International CAPM is the only asset pricing model that tries to explain the assets' returns in the international context. Since the PPP condition does not hold empirically, researchers introduced a new risk factor into the equation besides the market risk. Due to their high correlation with the PPP deviations, the deviations from UIP are considered the proxies for the foreign exchange risk premia 
in the International CAPM. Even if this model is very appealing due to its powerful intuitive explanations, its empirical failure is an established fact in the literature. It does not behave considerably better than the classic CAPM.

This essay argues that the failure of the International CAPM is due to very low (in absolute value) foreign exchange premia. Since the currency risk premia are very close to zero, they become statistically insignificant in explaining equity returns and lead to the rejection of the International CAPM. The first essay enables us to predict the values of the risk premia. If one can take into consideration only the periods of time when the risk premia are larger in absolute value (i.e. conditioning on the predicted currency risk premia), one can appraise this statement.

I use a GMM approach. My specification of this conditional version of the International CAPM gives better results than the classic International CAPM. The null hypothesis of a valid model is rejected for the unconditional CAPMs and definitely accepted for the conditional version of the International CAPM. I find that indeed the rejection of the International CAPM is due to the proxy for the foreign exchange risk being too small in absolute value.

The last and fifth chapter concludes. 


\section{Chapter 2: Combining Mean Reversion and Momentum Trading Strategies in Foreign Exchange Markets}

\section{Introduction}

Foreign exchange market trading strategies have attracted much attention, especially since Fama (1984) introduced the "forward puzzle," which argues that forward exchange rates are biased predictors of spot exchange rates. This paper sets forth a new strategy in the foreign exchange (FX) markets that combines mean reversion and momentum. Even though the strategy was originally designed for equity markets, I find that it produces higher Sharpe ratios than traditional FX strategies.

The starting point of this paper, the "forward puzzle," results from the rejection of the uncovered interest parity (UIP) theory. UIP states that the change in the exchange rate should incorporate any interest rate differentials between the two currencies. A large literature exists examining if and when UIP holds. ${ }^{1}$ This paper tries to find a pattern in the deviations from UIP and to explore the similarity between this pattern and that of stock returns. The literature reveals what looks like mean reversion and momentum in both markets. A long-run mean reverting pattern in currency values has been uncovered by Engel and Hamilton (1990); a short-term momentum effect generates profitability in FX market trading (Okunev and White, 2003). ${ }^{2}$ Chiang and Jiang (1995) notice that foreign exchange returns show strong positive correlations in the short-run (momentum behavior) and negative correlations in the long-run (mean reverting behavior). This paper generates abnormal returns by employing a strategy that combines the long-run and short-run patterns of the deviations from UIP.

The success of the combined momentum-mean reversion strategy brings about another interesting issue: the puzzling relationship between stock and FX markets. The similarities between the stock and FX markets are perplexing because macroeconomic fundamentals explain stock returns, but not exchange rates (Meese and Rogoff, 1983). Traditional theory dictates that two markets not relying on the same fundamental variables cannot behave similarly. Yet, I find the two markets comparable. This result is

\footnotetext{
${ }_{2}^{1}$ For more details on UIP, see for instance Froot and Frankel (1989).

${ }^{2}$ Okunev and White actually use a moving average rule to create profits for the speculators on the FX market, but they name this "a simple momentum strategy." The strategy in my paper is different from theirs.
} 
in line with early studies that depict similar empirical regularities in FX and stock markets (Mussa, 1979). One possible explanation springs from Engel and West (2005), who find that exchange rates explain macroeconomic fundamentals, not the reverse. This finding, corroborated with the finding that fundamentals explain stock returns, provides one possible channel for the relation between the two analyzed markets. Another fascinating explanation is that the risk factors affecting both stock and FX returns remain unknown but are somehow connected. An additional explanation is that similar behavioral biases operate in both markets, leading to similar inefficiencies.

To explore the similarities between the stock and FX markets, I first consider the non-parametric approach that Jegadeesh and Titman (1993) exploit. These papers construct portfolio deciles based on previous months' returns and choose a winner and a loser decile. By buying the winner and selling the loser a zero-investment portfolio is constructed and this portfolio is held for less than a year. The authors find that the return on their zero-investment portfolio is always positive. If this portfolio is held for more than a year, however, the return becomes zero or negative. The aforementioned nonparametric strategy is used in the FX market by identifying a winner and a loser currency based on previous deviations from UIP. I find that the winner continues to have high returns and the loser low returns for the subsequent 9-12 months, but, in the subsequent 4-5 years, the winner and loser portfolios switch positions. However, one cannot combine mean reversion and momentum strategies with this approach.

Balvers and $\mathrm{Wu}$ (2006) use an alternative approach to generate trading profits in the stock market: a parametric strategy. They consider the effect of momentum and mean reversion jointly and conclude that the resulting strategy can lead to significant profits when applied to the stock markets of 18 developed countries. A contrarian strategy or a momentum strategy by itself leads to lower abnormal returns than the combination strategy. I find that the parameters obtained for the FX market are quantitatively similar to those for the stock market; hence we expect similar trading strategy returns for the zero investment portfolios. The FX market returns have lower volatility than equity market returns. Consequently, I consider the Sharpe ratios, which allow me to compare risk-toreward profiles of the same strategy, but in the two different markets. The Sharpe ratios obtained in the FX market are significantly larger than those obtained in the stock market. 
The paper is organized as follows. The second section describes the data and presents preliminary results showing that deviations from UIP exhibit momentum initially and subsequent mean reverting behavior. The third section describes the model and the fourth examines the model empirically and compares the results to the existing literature. The final section concludes.

\section{Data description and preliminary statistics}

\subsection{Data description}

The data set consists of the 1-month forward and spot exchange rates from the Bank of International Settlements and Datastream. Due to availability, the data come from two sources: for the period December 1978 - December 2001 from the BIS dataset, and for January 2002 - February 2008 from Datastream. I obtain monthly data for the Canadian Dollar, German Mark/Euro, UK Pound and Japanese Yen. I focus on well-developed currencies with liquid markets, in which currency speculation can be easily implemented. Due to data availability, the literature on the FX market usually only covers these currencies. I work with December 1978 through February 2008 as the time period. ${ }^{3}$ The US Dollar serves as the home currency.

The monthly equity market returns are obtained from the Morgan Stanley Capital International (MSCI) Barra equity market price indexes for the same set of four developed countries plus the US. The sample period is December 1978 through February 2008. The risk free rate is the one-month Treasury bill rate (from Ibbotson Associates), obtained from Kenneth French's website.

\subsection{Interest parity conditions}

UIP states that the currencies at a forward premium should appreciate. The "forward puzzle" suggests that the exact opposite happens: these currencies actually tend to depreciate. An investor who borrows money in their home country (with an interest rate of $r_{t}$ ) and lends it in another country with a higher interest rate $\left(r_{t}^{i}\right)$ should expect a zero

\footnotetext{
${ }^{3}$ Most of the literature only considers data on the FX market starting in the 1970's, after the collapse of the Bretton Woods System. Due to data availability, the sample in this paper starts in December 1978. The choice of currencies was limited to avoid multicollinearity problems in the parameters' estimation (i.e., this paper considers currencies that are not highly correlated with each other).
} 
return due to the changes in exchange rate (denoted at time $t$ by $S_{t}^{i}$, in units of home country currency per foreign country currency) . In other words:

$1+r_{t}=\left(1+r_{t}^{i}\right) \frac{E\left(S_{t+1}^{i}\right)}{S_{t}^{i}}$,

With this strategy, investors leave their position uncovered from $t$ to $t+1$ and only make arrangements to change the foreign currency into domestic currency at time $t+1$. The UIP states that the markets equilibrate the return on the domestic currency asset with the expected yield of the uncovered position in the foreign currency. If the investors leave nothing to chance and make arrangements to convert foreign to domestic at $t+1$ by using a forward exchange rate $F_{t}$, absence of riskless arbitrage profits implies that:

$$
1+r_{t}=\left(1+r_{t}^{i}\right) \frac{F_{t}^{i}}{S_{t}^{i}},(2.2)
$$

Equation (2.2) is known as Covered Interest Parity (CIP). Taking logs of (1) and (2) and ignoring expectations, we obtain:

$r_{t}-r_{t}^{i}=s_{t+1}^{i}-s_{t}^{i}$, with $s_{t}^{i} \equiv \ln S_{t}^{i}$

$r_{t}-r_{t}^{i}=f_{t}^{i}-s_{t}^{i}$, with $f_{t}^{i} \equiv \ln F_{t}^{i}$

If both conditions hold, it follows that:

$s_{t+1}^{i}-s_{t}^{i}=f_{t}^{i}-s_{t}^{i}$,

Equation (2.5) accounts for the interest rate differential implied by the CIP condition. ${ }^{4}$

This paper is concerned with the deviations from UIP, denoted by $y_{t}^{i}$ and defined as follows:

$y_{t+1}^{i}=\left(s_{t+1}^{i}-s_{t}^{i}\right)-\left(f_{t}^{i}-s_{t}^{i}\right)=s_{t+1}^{i}-f_{t}^{i}$,

Table 2.1 presents summary descriptive statistics of the returns for UIP positions in the four currencies and for various similar positions in the stock market: annualized mean returns, standard deviations and Sharpe ratios. Given the low mean returns in the FX market (relative to the stock market), leverage is widely used in practice to provide the desired mean returns. The Sharpe ratios provide the proper comparison between the FX and equity markets since they remain invariant to the degree of leverage.

\footnotetext{
${ }^{4}$ The CIP is the condition used by large banks for determining the exchange rates and interest rates at which trading is actually conducted. See for instance Taylor (1987) and Baba and Packer (2009).
} 
Panel A displays summary statistics for UIP positions in the FX market, Panel B describes stock market excess returns computed from the MSCI Barra price indexes, and Panel C shows descriptive statistics for a strategy of buying US index and short selling a foreign index, the stock market counterpart of the UIP positions in the FX market. The mean returns for the UIP positions in panel A range from -1.66 to 1.81 percent and the standard deviations from 4.68 to 10.19 percent. In Panel B, the mean returns for the stock market indexes range from 7.08 to 12.00 percent and standard deviations from 14.76 to 22.03 percent. Evidently, more dispersion exists in the data for the stock market returns than for the FX market, as expected from the literature (Burnside et al., 2008; Fong, 2010). By taking the US stock market as the benchmark country (by analogy to the FX positions), the strategy that Panel $\mathrm{C}$ proposes gives very low mean returns (ranging from -0.08 to 4.29 percent), and very high standard deviations (from 13.51 to 22.32 percent); this again shows a much higher dispersion in the equity market than in the FX market. The Sharpe ratios are relatively low in Panels A and C and relatively high in Panel B.

\subsection{Confirming mean reversion and momentum}

To check for mean reversion and momentum, one can use the Jegadeesh and Titman (1993) strategy easily and effectively by applying this strategy to the deviations from UIP. The strategy considers the cumulative deviations from UIP for every currency over the previous $\mathrm{J}$ months (where $\mathrm{J}$ takes the values of 6 , 9, or 12). Each month I rank the currencies on the basis of past deviations from UIP and the currency with the highest cumulative return classifies as the "winner," while the currency with the lowest return becomes the "loser." For these currencies I compute the cumulative deviations from UIP

over the subsequent $\mathrm{K}$ months (where $\mathrm{K}$ is 6,9 , 12, 24, 36, 48, and 60). I assign the winner and loser for every month; consequently, the holding periods overlap. Figure 2.1 summarizes the results for all permutations of this strategy.

From the graph, one can ascertain effortlessly that the winner's mean return starts out positive and continues to be positive until the momentum effect disappears (after about one year). The loser's return appears to be a mirror image of the winner's return. Starting around year four, the results are reversed and the losers outperform the winners. These results do not differ from the results on the stock market (De Bondt and Thaler, 
1985; Jegadeesh and Titman, 1993; Balvers et al., 2000; Friesen et al., 2009). I am the first to implement a strategy of combining mean reversion and momentum in the FX market. This strategy generates significant abnormal returns in this market, as shown in the following sections.

\section{Model and parameter estimation}

\subsection{Model}

Fama and French (1988) and Summers (1986) consider a simple model for stock prices (their natural $\log$ is represented by $x$ ) that is the sum of a random walk and a stationary component. The stationary component classifies as a first-order autoregressive process that represents the long temporary swings in stock prices (characterized by coefficient $\delta$ ). The parameter $\mu$ captures the random walk drift component. Similarly, but adding a coefficient for the momentum effect $\rho$, Balvers and $\mathrm{Wu}$ (2006) construct the log of stock prices (with dividends added and reinvested) as:

$x_{t}^{i}=\left(1-\delta^{i}\right) \mu^{i}+\delta^{i} x_{t-1}^{i}+\sum_{j=1}^{J} \rho_{j}^{i}\left(x_{t-j}^{i}-x_{t-j-1}^{i}\right)+\varepsilon_{t}^{i}$,

They note that the $\log$ of the price with dividends reinvested implies that the return is $y_{t}^{i}=x_{t}^{i}-x_{t-1}^{i}$ and that the log of the price equals the cumulative return after correction for market risk:

$x_{t}^{i}=\sum_{s=1}^{t} y_{s}^{i}$

I use equation (2.7) to find abnormal returns in the FX market. The $\delta^{i}$ represent the speed of mean reversion and can differ by country, while the $\rho_{j}^{i}$ represent the momentum strength and can vary by country and by lag. The parameter $\mu^{i}$ also varies by country.

From equation (2.7), the return of my strategy is:

$y_{t}^{i}=-\left(1-\delta^{i}\right)\left(x_{t-1}^{i}-\mu^{i}\right)+\sum_{j=1}^{J} \rho_{j}^{i}\left(x_{t-j}^{i}-x_{t-j-1}^{i}\right)+\varepsilon_{t}^{i}$,

The models proposed by Fama and French (1988) and Summers (1986) consider

only mean reversion, hence all the $\rho_{j}^{i}$ in their models equal zero. In equation (2.9) it is 
theoretically possible for $\rho_{j}^{i}$ and $\delta^{i}$ to be outside the interval $[0,1]$, but empirically I expect them to fall inside the interval. The first part of equation (2.9) represents the mean reversion component, while the second part represents the momentum effect. Therefore, one can write my model as:

$y_{t}^{i}=M R V_{t}^{i}+M O M_{t}^{i}+\varepsilon_{t}^{i}$,

If the $\rho_{j}^{i}$ and $1-\delta^{i}$ diverge from zero, then the mean reversion and momentum effects should be correlated. In order to check for that correlation, I consider the simple model in which $\rho_{j}^{i}$ only varies by country (as does $\delta^{i}$ ):

$y_{t}^{i}=-\left(1-\delta^{i}\right)\left(x_{t-1}^{i}-\mu^{i}\right)+\rho^{i}\left(x_{t-1}^{i}-x_{t-J-1}^{i}\right)+\varepsilon_{t}^{i}$,

Taking into consideration the definitions of $M O M$ and $M R V$, equation (2.9) and stationarity imply:

$\operatorname{cov}\left(M R V_{t}^{i}, M^{i} M_{t}^{i}\right)=-\left(1-\delta^{i}\right) \rho^{i}\left[1-\operatorname{corr}\left(x_{t}^{i}, x_{t-J}^{i}\right)\right] \operatorname{var}\left(x_{t}^{i}\right)<0,{ }^{5}$

Since $\delta^{i}$ and $\rho^{i}$ both lie between 0 and 1, the covariance between the two effects has a negative sign. Intuitively, a positive momentum effect pushes the return upward, while the mean reversion effect tends to bring the cumulative return back to its mean, so downward. Therefore, one can anticipate a negative correlation between the two effects.

Omitting one of the two effects leads to biased estimation of the parameters. Omitting mean reversion requires $\delta^{i}=1$ in equation (2.11):

$y_{t}^{i}=\alpha_{M O M}^{i}+\beta_{M O M}^{i}\left(x_{t-1}^{i}-x_{t-J-1}^{i}\right)+\varepsilon_{t, M O M}^{i}$

Consequently, plim $\beta_{M O M}^{i}=\rho^{i}-\left(1-\delta^{i}\right) \frac{\left[1-\operatorname{Corr}\left(X_{t-1}^{i}, X_{t-1}^{i}-X_{t-J-1}^{i}\right)\right] \operatorname{Var}\left(X_{t-1}^{i}\right)}{\operatorname{Var}\left(X_{t-1}^{i}-X_{t-J-1}^{i}\right)}<\rho^{i}$.

Hence, the measured impact of momentum is smaller if mean reversion is omitted. By the same logic, if one runs the following equation assuming no momentum, $\rho^{i}=0$ in equation (2.11):

$y_{t}^{i}=\alpha_{M R V}^{i}+\beta_{M R V}^{i} x_{t-1}^{i}+\varepsilon_{t, M R V}^{i}$

Then: $p \lim \beta_{M R V}^{i}=-\left(1-\delta^{i}\right)+\rho^{i} \frac{\left[1-\operatorname{Corr}\left(X_{t-1}^{i}, X_{t-1}^{i}-X_{t-J-1}^{i}\right)\right] \operatorname{Var}\left(X_{t-1}^{i}\right)}{\operatorname{Var}\left(X_{t-1}^{i}-X_{t-J-1}^{i}\right)}>-\left(1-\delta^{i}\right)$.

\footnotetext{
${ }^{5}$ For a complete derivation, check Balvers and $\mathrm{Wu}(2006)$.
} 
So the mean reversion coefficient estimation is inconsistent and implies a biased upward half-life, leading to a possible spurious rejection of mean reversion. ${ }^{6}$

\subsection{Parameter estimation}

The model in equation (2.9) considers a total number of parameters equal to $9(\mathrm{~J}+2)$ $\left(9 \delta^{i}, 9 \mu^{i}\right.$ and $\left.9 \mathrm{~J} \rho_{j}^{i}\right)$. That is a very large number of parameters to estimate. Consequently, in order to avoid multicollinearity problems and to improve efficiency, I only allow $\mu^{i}$ to differ by country (which accounts for possible "mispricing" at the beginning of the period), while:

$$
\begin{aligned}
& \delta^{i}=\delta \\
& \rho_{j}^{i}=\rho
\end{aligned} \quad, \text { for all } i \text { and } j
$$

I use the full range of my sample and obtain the parameter estimates using a pooled model and $\mathrm{J}=12$. Table 2.2 presents the results.

The first column reports the parameter estimates when allowing both mean reversion and momentum. Both coefficients are statistically significant. The mean reversion coefficient $\delta$ pooled across countries equals 0.9859 , implying a half-life of 45 months. The speed of mean reversion $1-\delta$ is significantly positive and equals 0.0141 . The momentum parameter $\rho$ pooled across countries is a statistically significant and positive 0.0428 . These results lie very close to those obtained for the stock market by Balvers and $\mathrm{Wu}$ (2006): the half-life for the combination strategy remains the same for the two markets, and the momentum effect is stronger in the FX market $(\rho=0.043$ compared to 0.023 in the stock market).

The second and third columns show the parameter estimates for each of the two pure strategies. The mean reversion coefficient increases in the pure mean reversion strategy (0.9944) leading to a very long half-life of 124 months. The theoretical asymptotic bias in the mean reversion coefficient when omitting momentum is $\rho \frac{\operatorname{cov}\left(x_{t-1}, x_{t-1}-x_{t-J-1}\right)}{\operatorname{var}\left(x_{t-1}\right)}=0.009$. Empirically, the difference stays positive and very close to the theoretical value $(0.0085)$. In the pure momentum strategy, the strength of momentum

\footnotetext{
${ }^{6}$ Half-life is the expected time for the analyzed stochastic variable to return half of the way toward the equilibrium level, $\mu$. It is computed as $\ln (0.5) / \ln (1-\delta)$.
} 
is indeed smaller (still positive and statistically significant) and equal to 0.0345 (the momentum effect is stronger in the FX market than in the stock market even in this case). The theoretical asymptotic bias of the momentum coefficient $\rho$ is $-(1-\delta) \frac{\operatorname{cov}\left(x_{t-1}, x_{t-1}-x_{t-J-1}\right)}{\operatorname{var}\left(x_{t-1}-x_{t-J-1}\right)}=-0.0083$ and again it lies very close to the empirical bias ($0.0083)$.

If we compare columns 1 and 2 of Table 2.2, the half-life for the combination strategy diminishes. Intuitively, this is expected due to two effects of momentum: the first initial effect of momentum is positive and causes the downturn to come later and the second momentum effect starts after the downturn and shortens the half-life.

The remainder of Table 2.2 reports the variance decomposition. From equation (2.10) we observe that:

$$
\operatorname{var}\left(y_{t}^{i}\right)=\operatorname{var}\left(M R V_{t}^{i}\right)+\operatorname{var}\left(M O M_{t}^{i}\right)+2 \operatorname{cov}\left(M R V_{t}^{i}, M O M_{t}^{i}\right)+\sigma_{\varepsilon}^{2},
$$

The variance of the returns is determined in large part by the errors (hence the small $\mathrm{R}^{2}$ of 3.89 percent) and the rest by the variance of mean reversion, momentum and their covariance. The small coefficient of determination is actually higher than that obtained for the stock market. ${ }^{7}$

The variance of momentum explains 4.26 percent of the variation in the returns from UIP, while the variance of mean reversion explains only about one-third as much of the variation in returns (1.29 percent). For the stock market, the two effects hold similar importance in explaining the returns. Mean reversion remains a very important component and should not be disregarded as follows for instance from the bias in the momentum coefficient when mean reversion is omitted.

The correlation between the two effects is theoretically and empirically negative and the same size as that obtained for the stock market ( -0.35 in both markets).

\section{Trading strategies}

I employ a mean reversion - momentum combination strategy, currently developed only for the stock market, for the FX market. I use the following variation of equation (2.9) by only allowing $\mu$ to change by country, while $\rho$ and $\delta$ stay fixed by country and lags:

\footnotetext{
${ }^{7}$ Balvers and $\mathrm{Wu}(2006)$ obtain $2.12 \%$.
} 
$y_{t}^{i}=-(1-\delta)\left(x_{t-1}^{i}-\mu^{i}\right)+\sum_{j=1}^{J} \rho\left(x_{t-j}^{i}-x_{t-j-1}^{i}\right)+\varepsilon_{t}^{i}$,

Based on the first $1 / 3^{j=1} \quad$ of the sample, using OLS, I estimate the return $y_{t}^{i}$

for each currency. Max denotes the currency with the highest expected return and Min denotes the currency with the lowest expected return. I form a portfolio by taking a long position on Max and a short position on Min (denoted by Max - Min) and I hold these positions for the next $\mathrm{K}$ months (where $\mathrm{K}$ can be 1, 3, 6, 9, and 12). In each subsequent period, I apply the same procedure, updating the sample period by one month each time. ${ }^{8}$ There are two exceptions to this strategy: if all expected returns are positive, I take a long position on Max only and hold it for $\mathrm{K}$ months; if all returns are negative, I take a short position on Min and hold it for K months. This way, the USD is effectively incorporated into the strategy. For easier representation, the tables report "Max - Min" for the portfolio return. Again, due to a very large number of parameters to estimate, I only allow $\mu^{i}$ to change by country.

Due to overlapping periods, when finding the returns of the strategy, I employ the same procedure as Jegadeesh and Titman (1993). If $\mathrm{K}=3$ for instance, at each moment $\mathrm{t}$, the strategy gives weights of $1 / 3$ to each of the portfolios decided at times $t-2, t-1$ and $\mathrm{t}$ (the positions chosen at $\mathrm{t}-3$ are closed). Hence, I revise the weights (of $1 / \mathrm{K}$ ) each month, carrying positions for the remaining months, cancelling old positions and deciding on new ones.

For the results of the pure momentum and pure mean reversion strategies, one takes the decisions in the exact same way and using the same equation (2.13), but $\rho$ is assumed to equal zero for the pure mean reversion strategy and $\delta$ is assumed to equal one for the pure momentum strategy.

Due to overlapping data when $\mathrm{K}>1$, the standard errors might be biased downward. Hence, the standard errors are corrected for autocorrelation and heteroskedasticity using Newey - West (1987) adjustment (with K - 1 lags).

\subsection{The pure mean reversion strategy}

\footnotetext{
${ }^{8}$ So I use as a first sorting period months 1 to $1 / 3$ of the sample, then months 1 to $1 / 3$ of the sample +1 month and so on, rolling the sample forward.
} 
Table 2.3 reports averages and standard errors for the annualized returns of Max and Max - Min portfolios for different holding periods K. Panel A presents the results for the pure mean reversion strategy. The mean return for the zero-investment portfolio ranges from around 1.6 percent for $K=12$ to 3.1 percent for $K=1$.

A similar mean reversion strategy has not been implemented in the FX markets. However, Rogoff (1996) finds that the PPP does revert to a long-run mean and typically the literature reports a half-life of three to five years. A study prepared by Deutsche Bank (2007) notices that PPP is one of the best fundamentals that can forecast the exchange rates and constructs a contrarian strategy. Depending on the time period considered, they obtain mean excess returns ranging from 3.8 to 4.3 percent. The pure mean reversion strategy this paper constructs leads to lower average returns. However, the two strategies are different in that the former presents a contrarian strategy based on reversion to the PPP.

\subsection{The pure momentum strategy}

Panel B presents the annualized mean returns and standard errors for Max and Max Min portfolios for different combinations of $\mathrm{K}$ and $\mathrm{J}$ when $\delta=1$. The trend of the mean returns is very similar to that obtained for the stock market by Balvers and $\mathrm{Wu}(2006)^{9}$, but the annualized average Max - Min portfolio is usually smaller for the FX market (as expected). Some of the average returns for the zero-investment portfolio are negative.

Since the trend is similar for different $\mathrm{J}$, I only present the case of $\mathrm{J}=12$. The Max - Min mean portfolio return ranges from a statistically significant 5 percent for $K=9$ to 9 percent for $\mathrm{K}=3$. These returns are similar to the 5-7 percent per year obtained by Okunev and White (2003) for their simple momentum-like strategy. However, in some cases, the mean returns here outperform the Okunev and White (2003) strategy. This result is fascinating considering the fact that they employ a strategy designed for the FX market, while I use a strategy originally designed for the stock market.

\footnotetext{
${ }^{9}$ Note that for the strategy developed in this paper, I make a comparison with the results obtained by Balvers and $\mathrm{Wu}$ (2006). They conduct their research on a sample of equity market indexes from 18 countries from 1969 through 1999. The reader should bear these differences in sample selection in mind for the following discussions regarding the comparison between the FX and equity markets when using the aforementioned strategy.
} 


\subsection{The combination strategy}

Table 2.4 presents the annualized mean returns, standard errors and Sharpe ratios for the combination strategy. For comparison, the table also reports the results using the same strategy in the stock market for each combination $(\mathrm{J}, \mathrm{K})$ as obtained by Balvers and $\mathrm{Wu}$ (2006). The table also shows the outcomes of the strategy after transaction costs. Including the no-transaction costs rows of the table allows a more direct comparison between the stock and FX markets. Also, the transaction costs this paper employs are only estimated, not actual. FX market transaction costs are not very large. According to Szakmary and Mathur (1997) they range from 0.05 to 0.2 percent for developed countries. I consider the maximum of a 0.2 percent transaction cost, which is subtracted from the return each time a purchase or short sell of a new currency occurs.

The no-transaction costs strategy for $\mathrm{J}=12$ generates a mean return for the zeroinvestment portfolio of around $10-12$ percent. ${ }^{10}$ Transaction costs do not significantly alter the results.

The comparison between these results and the results obtained through the pure mean reversion strategy is not straightforward, since the latter strategy assumes $\mathrm{J}=0$. One can study this comparison by computing an overall average for the combination strategy for each $\mathrm{K}$ and finding the difference between that average and the mean zero-investment portfolios in Table 2.4. For all K's, the mean returns increase with the use of the combination strategy. Comparing the average returns between the combination strategy and the momentum strategy is much easier. There are 25 pairs $(\mathrm{J}, \mathrm{K})$ for each of the two strategies and for all the combination strategy generates higher mean returns.

The comparison between the FX market and the stock market is one of the main objectives of this paper. As discussed previously, the Sharpe ratio is the best metric for comparing the two different markets. In all cases, the Sharpe ratio for the FX market is

\footnotetext{
${ }^{10}$ Following Cochrane (2005, p. 447), I check how the mean returns compare to the theoretical returns. For the combination strategy, using different $\mu^{i}$ and the same $\delta$ and $\rho$ (across countries and momentum lags), I obtain the theoretical return. I use the results from Table 2. The procedure proposed by Cochrane multiplies the standard deviation of the return, $\sqrt{0.000593}$, by the standardized expected return of the currency in the top $4^{\text {th }}$ of the standard normal distribution $(0.3178$, obtained from the expected return of the standard normal variable over the interval 0.6745 to infinity), and then by the square root of $R^{2}(\sqrt{0.0389})$. I obtain an expected annualized return for the top currency of $14.08 \%$. After following the same procedure for the bottom currency, I obtain the annualized theoretical return of the Max - Min portfolio to be $28.16 \%$. This theoretical return is larger than the $9.9 \%$ annualized return obtained in Table 4 , for the combination $\mathrm{J}=12$ and $\mathrm{K}=1$. In this light the returns obtained in this paper are not too high.
} 
larger than that for the stock market. On average, standard errors for the FX combination strategy are 33 percent of the standard errors for the stock combination strategy, while the mean returns for FX are around 80 percent of the mean return for stocks. This gives Sharpe ratios around 2.5 times higher for the FX than for the stock market. ${ }^{11}$

Different strategies have been employed in the equity market literature. For a buyand-hold strategy, the Sharpe ratio for the world market is 0.447 and that for the US is 0.644, according to Balvers et al. (2000). So the results that derive from using this combination strategy for the stock market are not unusual. Balvers et al. (2000) also apply two mean reversion strategies in the stock market: their own strategy, and DeBondt and Thaler's (1985) contrarian strategy. The Sharpe ratios obtained are 0.425 and 0.230 respectively. In Table 2.4 , for 18 out of $25(\mathrm{~J}, \mathrm{~K})$ combinations the stock market has higher Sharpe ratios than the Balvers et al. (2000) strategy and, for 24 out of 25, higher Sharpe ratios than the DeBondt and Thaler (1985) strategy. Hence the combination strategy produces much higher Sharpe ratios than other strategies employed in the stock market. Moreover, usually it produces Sharpe ratios 2 or 3 times larger than the DeBondt and Thaler (1985) strategy. I next compare the Sharpe ratios for the combination strategy in the FX market to Sharpe ratios for other strategies in the FX market.

In the FX market, perhaps the most common strategy is carry trade. Burnside et al. (2010) obtain an average annual return of 4.80 percent and a Sharpe ratio of 1.060. When considering transaction costs, the mean returns in Burnside et al. (2010) only decrease to 4.44 percent, while the Sharpe ratio falls to 0.866 . These results confirm that taking transaction costs into consideration in the FX market does not substantially modify the abnormal returns obtained, or the Sharpe ratios. Other strategies implemented in the FX market are technical trading rules. LeBaron (1999) finds annualized Sharpe ratios ranging from 0.67 to 0.96 for a dynamic trading rule strategy. ${ }^{12}$ The results obtained by implementing the combination strategy usually outperform other strategies in the FX market. When creating the strategy that combines mean reversion and momentum, the

\footnotetext{
${ }^{11}$ These differences between the two markets are typical. For instance, Okunev and White (2003) report annualized mean returns of $5-6$ percent and standard errors of $0.006-0.008$ for a momentum strategy in the FX market. Chan et al. (2000) report an annualized mean return for a momentum strategy implemented on international stock market indices of 13 percent and standard error of 0.039 for a holding period of 4 weeks.

${ }^{12}$ Neely (2002) and Harris and Yilmaz (2009) obtain similar returns when further investigating the trading rules' profitability.
} 
average of annualized mean returns obtained for $\mathrm{J}<18$ is 14.03 percent for no transaction costs and 10.06 percent when transaction costs are included. The average Sharpe ratio is 1.57 and 1.12 respectively. When $\mathrm{J}=18$, the momentum effect has already passed, so the mean returns and Sharpe ratios of the strategy are noticeably lower.

The stock market Sharpe ratios are not unusual, but significantly higher when one uses the combination strategy instead of other strategies. Similarly, the FX market results for the combination strategy outperform other strategies employed in the FX market, and also provide significantly higher Sharpe ratios than those found for the stock market. ${ }^{13}$

\section{Conclusions}

This paper employs a trading strategy, previously applied only to the stock market that creates abnormal returns in the FX market. By running a simple parametric test, I find that UIP deviations follow mean reversion and momentum. In the FX market the half-life of mean reversion is very close to that obtained for the stock market, while the momentum effect is stronger than in the stock market. The combination strategy creates significant abnormal mean returns (slightly underperforming those of the stock market) and Sharpe ratios usually much higher than in the stock market. The results are also strong in comparison to strategies developed specifically for FX markets. Transaction costs do not alter the results significantly. I consider developed countries only. The portfolio I construct should be even more profitable if the currency choices are more numerous.

This paper contributes to the literature not only by applying a new strategy in the FX market, but by applying one originally designed for the stock market. The FX literature considers mean reverting behavior toward PPP values and momentum trading strategies based on moving average rules. I bring a fresh perspective to understanding FX market dynamics by considering risky asset returns, instead of macroeconomic fundamentals. This allows for the creation of a strategy based on returns (computed in this case from deviations from UIP) and a direct comparison of the exploitability of the return patterns between the FX and the stock market. Up to now strategies employed in

\footnotetext{
${ }^{13}$ Results of robustness checks (different time periods, parameters allowed to vary by country and/or lag) do not significantly change the results and are available upon request.
} 
one market have not been successfully implemented in the other market, likely due to fundamental differences between the two markets. For instance, technical trading rules were found to be completely useless in the stock market since the publication of Fama and Blume (1966), but profitable in the FX market (Sweeney, 1986; Szakmary and Mathur, 1997; and LeBaron, 1999), suggesting major differences between the markets. The striking results here, on the other hand, raise the question of why the two markets behave so similarly.

Many papers challenge the efficiency of the two markets. Neely (2002) examines the possibility that the FX market is inefficient due to Central Bank intervention. He reviews the literature regarding the abnormal returns obtained in the FX market through technical rules, but not existing in the stock market. Presumably, they are due to Central Bank interventions. Neely (2002) challenges that finding. This paper finds further evidence supporting Neely's claim since the FX and stock market inefficiencies have similar patterns.

One is left to wonder whether the two markets are indeed inefficient, or whether, in fact, there exists an unobserved risk factor that explains these returns. A possible theory is the overreaction hypothesis proposed from a behavioral perspective (e.g. DeBondt and Thaler, 1985) for the stock market: individuals tend to "overreact" to recent information, creating momentum. After some time, extreme movements in prices will be followed by a return to fundamentals, leading to movements in the opposite direction, creating mean reversion. In foreign exchange markets, Dornbusch (1976) shows that exchange rates tend to "overshoot" in their response to monetary policies, but then revert to a long-run equilibrium. The correspondence between overreaction in the stock market and overshooting in the foreign exchange market may be responsible for the similarity in results in these two markets when the combined momentum and mean reversion strategy is applied. Examining this correspondence presents a promising direction for future research. 
Table 2.1

Summary Statistics

\begin{tabular}{lccc}
\hline & Mean & $\begin{array}{c}\text { Standard } \\
\text { Deviation }\end{array}$ & $\begin{array}{c}\text { Sharpe } \\
\text { Ratio }\end{array}$ \\
\hline Panel A. FX Market & 1.37 & 4.68 & 0.29 \\
Canada & 1.81 & 9.06 & 0.20 \\
UK & -1.66 & 10.19 & -0.16 \\
Japan & -0.49 & 9.42 & -0.05 \\
Germany & & & \\
\hline & & & \\
Panel B. Stock Market (buy and hold excess returns) & 11.37 & 14.76 & 0.77 \\
US & 11.45 & 19.58 & 0.59 \\
Canada & 12.00 & 18.14 & 0.66 \\
UK & 7.08 & 22.03 & 0.32 \\
Japan & 10.28 & 21.82 & 0.47 \\
Germany & & & \\
\hline & & & \\
Panel C. Stock Market (returns of holding the US and shorting the specific country ) & 13.51 & -0.01 \\
UK & -0.08 & 14.69 & -0.04 \\
Japan & -0.63 & 22.32 & 0.19 \\
Germany & 4.29 & 18.55 & 0.06 \\
\hline
\end{tabular}

This table reports summary statistics (annualized mean, standard deviation and Sharpe ratio) for deviations from UIP (Panel A), stock excess returns (Panel B) and stock returns for a strategy of buying US stock and short selling foreign country stock (Panel C). The mean and standard deviations are multiplied by 100 (so 1.37 should be read as 1.37\%). The deviations from UIP for the Canadian Dollar, German Mark/Euro, UK Pound and Japanese Yen relative to the US Dollar are computed as: $y_{t}^{i}=s_{t+1}^{i}-f_{t}^{i}$. The data are taken from Bank of International Settlements and Datastream. The stock returns are computed for the same four countries plus the US from the MSCI Barra indices. The sample period is December 1978 - February 2008. Panel B reports statistics for the excess returns, obtained by subtracting the one-month US Treasury (taken from Kenneth French's website). For the Sharpe ratios in Panels A and C, US is considered the benchmark country, so there is no need to subtract the average risk free rate. 


\section{Table 2.2}

\section{Model Parameters and Variance Decomposition}

\begin{tabular}{|c|c|c|c|c|c|c|}
\hline \multirow{2}{*}{$\begin{array}{l}\text { Moment } \\
\delta\end{array}$} & \multicolumn{2}{|c|}{ MRV \& MOM } & \multicolumn{2}{|c|}{ MRV only } & \multicolumn{2}{|c|}{ MOM only } \\
\hline & 0.9859 & $(0.0035)$ & 0.9944 & $(0.0033)$ & - & \\
\hline$\rho$ & 0.0428 & $(0.0059)$ & - & & 0.0345 & $(0.0056)$ \\
\hline $\operatorname{Var}\left(\mathrm{y}_{\mathrm{t}}\right)$ & 5.93E-04 & & $5.89 \mathrm{E}-04$ & & 5.93E-04 & \\
\hline$\sigma_{\varepsilon}^{2}$ & $5.70 \mathrm{E}-04$ & & $5.88 \mathrm{E}-04$ & & 5.77E-04 & \\
\hline $\operatorname{Var}\left(\mathrm{MRV}_{\mathrm{t}}\right)$ & $7.68 \mathrm{E}-06$ & & $1.19 \mathrm{E}-06$ & & - & \\
\hline $\operatorname{Var}\left(\mathrm{MOM}_{\mathrm{t}}\right)$ & $2.53 \mathrm{E}-05$ & & - & & $1.65 \mathrm{E}-05$ & \\
\hline $\operatorname{Corr}\left(\mathrm{MRV}_{\mathrm{t}}, \mathrm{MOM}_{\mathrm{t}}\right)$ & -0.35 & & - & & - & \\
\hline$\sigma_{\varepsilon}^{2} / \operatorname{Var}\left(\mathrm{y}_{\mathrm{t}}\right)(\%)$ & 96.10 & & 99.80 & & 97.23 & \\
\hline $\operatorname{Var}\left(\mathrm{MRV}_{\mathrm{t}}\right) / \operatorname{Var}\left(\mathrm{y}_{\mathrm{t}}\right)(\%)$ & 1.29 & & 0.20 & & - & \\
\hline $\operatorname{Var}\left(\mathrm{MOM}_{\mathrm{t}}\right) / \operatorname{Var}\left(\mathrm{y}_{\mathrm{t}}\right)(\%)$ & 4.26 & & - & & 2.78 & \\
\hline $\mathrm{R}^{2}(\%)$ & 3.89 & & 0.18 & & 2.75 & \\
\hline
\end{tabular}

This table reports the results of the following regression: $y_{t}^{i}=-(1-\delta)\left(x_{t-1}^{i}-\mu^{i}\right)+\sum_{j=1}^{J} \rho\left(x_{t-j}^{i}-x_{t-j-1}^{i}\right)+\varepsilon_{t}^{i}$. The data are pooled across currencies. I use the full sample 1979:01 - 2008:02. The first column presents the results for the above regression. The second column considers $\rho=0$, while the third column assumes $\delta=1$. The standard errors are presented in brackets. 
Table 2.3. Performance of the Pure Mean Reversion Strategy and the Pure Momentum Strategy

Panel A. The Pure Mean Reversion Strategy

\begin{tabular}{lccccccccccc}
\hline & \multicolumn{2}{c}{$\mathrm{K}=1$} & \multicolumn{2}{c}{$\mathrm{K}=3$} & \multicolumn{2}{c}{$\mathrm{K}=6$} & \multicolumn{3}{c}{$\mathrm{K}=9$} & \multicolumn{3}{c}{$\mathrm{K}=12$} \\
\hline Max & Ave & St error & Ave & St error & Ave & St error & Ave & St error & Ave & St error \\
Max-Min & 0.024 & 0.006 & 0.019 & 0.005 & 0.027 & 0.005 & 0.024 & 0.005 & 0.030 & 0.005 \\
& 0.031 & 0.006 & 0.025 & 0.006 & 0.025 & 0.006 & 0.022 & 0.006 & 0.016 & 0.006 \\
\hline
\end{tabular}

Panel B. The Pure Momentum Strategy

\begin{tabular}{|c|c|c|c|c|c|c|c|c|c|c|c|}
\hline & & \multicolumn{2}{|c|}{$\mathrm{K}=1$} & \multicolumn{2}{|c|}{$\mathrm{K}=3$} & \multicolumn{2}{|c|}{$\mathrm{K}=6$} & \multicolumn{2}{|c|}{$\mathrm{K}=9$} & \multicolumn{2}{|c|}{$\mathrm{K}=12$} \\
\hline & & Ave & St error & Ave & St error & Ave & St error & Ave & St error & Ave & St error \\
\hline \multirow{2}{*}{$\mathrm{J}=3$} & Max & 0.009 & 0.005 & 0.094 & 0.004 & 0.056 & 0.004 & 0.036 & 0.004 & 0.030 & 0.004 \\
\hline & Max-Min & -0.008 & 0.006 & 0.143 & 0.005 & 0.076 & 0.004 & 0.048 & 0.003 & 0.040 & 0.003 \\
\hline \multirow{2}{*}{$\mathrm{J}=6$} & Max & -0.028 & 0.005 & -0.001 & 0.004 & 0.044 & 0.004 & 0.035 & 0.004 & 0.024 & 0.004 \\
\hline & Max-Min & -0.067 & 0.007 & -0.014 & 0.004 & 0.054 & 0.003 & 0.038 & 0.003 & 0.022 & 0.003 \\
\hline \multirow{2}{*}{$\mathrm{J}=9$} & Max & 0.050 & 0.005 & 0.019 & 0.004 & 0.013 & 0.004 & 0.037 & 0.004 & 0.030 & 0.004 \\
\hline & Max-Min & 0.107 & 0.006 & 0.044 & 0.005 & 0.030 & 0.004 & 0.068 & 0.003 & 0.055 & 0.003 \\
\hline \multirow{2}{*}{$\mathrm{J}=12$} & Max & 0.027 & 0.005 & 0.039 & 0.004 & 0.032 & 0.004 & 0.023 & 0.004 & 0.036 & 0.004 \\
\hline & Max-Min & 0.081 & 0.006 & 0.086 & 0.004 & 0.064 & 0.003 & 0.045 & 0.003 & 0.069 & 0.002 \\
\hline \multirow{2}{*}{$\mathrm{J}=15$} & Max & -0.002 & 0.005 & 0.012 & 0.004 & 0.031 & 0.004 & 0.029 & 0.004 & 0.022 & 0.004 \\
\hline & Max-Min & -0.013 & 0.006 & 0.012 & 0.005 & 0.041 & 0.004 & 0.035 & 0.004 & 0.023 & 0.004 \\
\hline \multirow{2}{*}{$\mathrm{J}=18$} & Max & 0.006 & 0.005 & -0.008 & 0.004 & 0.003 & 0.004 & 0.018 & 0.004 & 0.016 & 0.004 \\
\hline & Max-Min & -0.018 & 0.007 & -0.032 & 0.005 & -0.010 & 0.004 & 0.016 & 0.004 & 0.015 & 0.004 \\
\hline
\end{tabular}

This table uses the following regression: $y_{t}^{i}=-(1-\delta)\left(x_{t-1}^{i}-\mu^{i}\right)+\sum_{j=1}^{J} \rho\left(x_{t-j}^{i}-x_{t-j-1}^{i}\right)+\varepsilon_{t}^{i}$. I use the full sample 1979:01-2008:02. Based on the first 1/3 of the sample, using OLS, I estimate the return $y_{t}^{i}$ for each currency. The currency with the highest expected return is denoted Max and that with the lowest expected return is 
denoted Min. The portfolio Max - Min is held for K months. The same procedure is applied in each subsequent period, each time updating the sample period by one month. The table presents annualized average returns (Ave) and Newey - West adjusted standard errors (St error) for the Max and Max - Min portfolios. The averages for the Max-Min portfolios are provided in the shaded areas. For Panel A, $\rho=0$ (the pure mean reversion strategy). For Panel B, $\delta=1$ (the pure momentum strategy). 
Table 2.4. Performance of the Combination Strategy

\begin{tabular}{|c|c|c|c|c|c|c|c|c|c|c|c|c|c|c|c|c|}
\hline & & \multicolumn{3}{|c|}{$\mathrm{K}=1$} & \multicolumn{3}{|c|}{$K=3$} & \multicolumn{3}{|c|}{$\mathrm{K}=6$} & \multicolumn{3}{|c|}{$\mathrm{K}=9$} & \multicolumn{3}{|c|}{$\mathrm{K}=12$} \\
\hline & & Ave & St error & Sharpe & Ave & St error & Sharpe & Ave & St error & Sharpe & Ave & St error & Sharpe & Ave & St error & Sharpe \\
\hline \multirow{3}{*}{$\mathrm{J}=3$} & FX (no trans costs) & 0.315 & 0.006 & 3.744 & 0.244 & 0.005 & 3.116 & 0.165 & 0.004 & 2.475 & 0.129 & 0.004 & 1.914 & 0.117 & 0.005 & 1.700 \\
\hline & FX (trans costs) & 0.275 & 0.006 & 3.267 & 0.205 & 0.005 & 2.598 & 0.126 & 0.004 & 1.860 & 0.089 & 0.005 & 1.301 & 0.078 & 0.005 & 1.099 \\
\hline & Stock & 0.098 & 0.019 & 0.327 & 0.128 & 0.017 & 0.503 & 0.145 & 0.015 & 0.622 & 0.140 & 0.014 & 0.642 & 0.125 & 0.014 & 0.600 \\
\hline \multirow{3}{*}{$\mathrm{J}=6$} & FX (no trans costs) & 0.192 & 0.006 & 2.140 & 0.199 & 0.006 & 2.140 & 0.176 & 0.006 & 2.011 & 0.124 & 0.006 & 1.466 & 0.096 & 0.006 & 1.112 \\
\hline & $\mathrm{FX}$ (trans costs) & 0.152 & 0.006 & 1.689 & 0.159 & 0.006 & 1.699 & 0.136 & 0.006 & 1.535 & 0.084 & 0.006 & 0.970 & 0.056 & 0.006 & 0.629 \\
\hline & Stock & 0.170 & 0.018 & 0.625 & 0.174 & 0.016 & 0.690 & 0.174 & 0.015 & 0.733 & 0.164 & 0.015 & 0.740 & 0.126 & 0.014 & 0.598 \\
\hline \multirow{3}{*}{$\mathrm{J}=9$} & FX (no trans costs) & 0.129 & 0.007 & 1.269 & 0.151 & 0.007 & 1.407 & 0.154 & 0.006 & 1.581 & 0.130 & 0.006 & 1.411 & 0.100 & 0.006 & 1.121 \\
\hline & FX (trans costs) & 0.089 & 0.007 & 0.871 & 0.111 & 0.007 & 1.029 & 0.114 & 0.006 & 1.155 & 0.090 & 0.006 & 0.956 & 0.059 & 0.006 & 0.651 \\
\hline & Stock & 0.140 & 0.018 & 0.511 & 0.161 & 0.017 & 0.633 & 0.163 & 0.015 & 0.687 & 0.117 & 0.014 & 0.533 & 0.084 & 0.014 & 0.402 \\
\hline \multirow{3}{*}{$\mathrm{J}=12$} & FX (no trans costs) & 0.099 & 0.007 & 0.998 & 0.115 & 0.007 & 1.066 & 0.119 & 0.007 & 1.140 & 0.114 & 0.006 & 1.173 & 0.105 & 0.006 & 1.115 \\
\hline & FX (trans costs) & 0.060 & 0.007 & 0.601 & 0.075 & 0.007 & 0.694 & 0.080 & 0.007 & 0.753 & 0.075 & 0.007 & 0.752 & 0.065 & 0.006 & 0.679 \\
\hline & Stock & 0.194 & 0.019 & 0.672 & 0.189 & 0.017 & 0.730 & 0.158 & 0.015 & 0.662 & 0.133 & 0.015 & 0.579 & 0.110 & 0.014 & 0.513 \\
\hline \multirow[t]{2}{*}{$\mathrm{J}=15$} & FX (trans costs) & 0.073 & 0.007 & 0.732 & 0.073 & 0.008 & 0.644 & 0.069 & 0.007 & 0.625 & 0.062 & 0.007 & 0.589 & 0.059 & 0.007 & 0.560 \\
\hline & Stock & 0.062 & 0.018 & 0.223 & 0.068 & 0.018 & 0.251 & 0.082 & 0.017 & 0.315 & 0.087 & 0.017 & 0.340 & 0.095 & 0.017 & 0.379 \\
\hline \multirow{3}{*}{$\mathrm{J}=18$} & FX (no trans costs) & 0.068 & 0.007 & 0.669 & 0.074 & 0.008 & 0.643 & 0.074 & 0.007 & 0.689 & 0.068 & 0.007 & 0.660 & 0.061 & 0.007 & 0.615 \\
\hline & $\mathrm{FX}$ (trans costs) & 0.028 & 0.007 & 0.275 & 0.034 & 0.008 & 0.295 & 0.034 & 0.007 & 0.315 & 0.028 & 0.007 & 0.269 & 0.021 & 0.007 & 0.208 \\
\hline & Stock & 0.074 & 0.018 & 0.261 & 0.112 & 0.018 & 0.406 & 0.127 & 0.018 & 0.463 & 0.130 & 0.017 & 0.485 & 0.124 & 0.017 & 0.475 \\
\hline
\end{tabular}

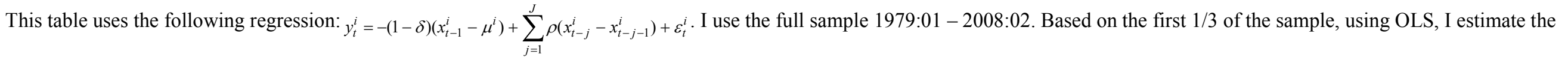

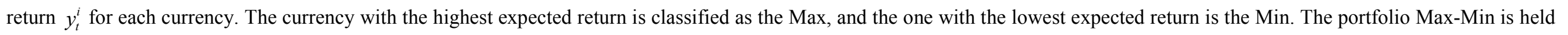

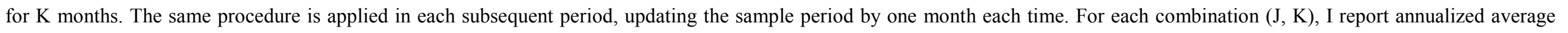

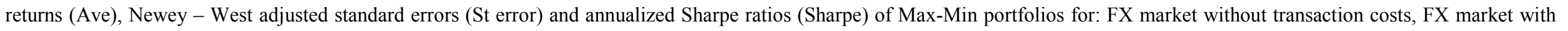
transaction costs, and stock market (as obtained from Balvers and $\mathrm{Wu}, 2006$ ). 
Figure 2.1. Average Annual Returns
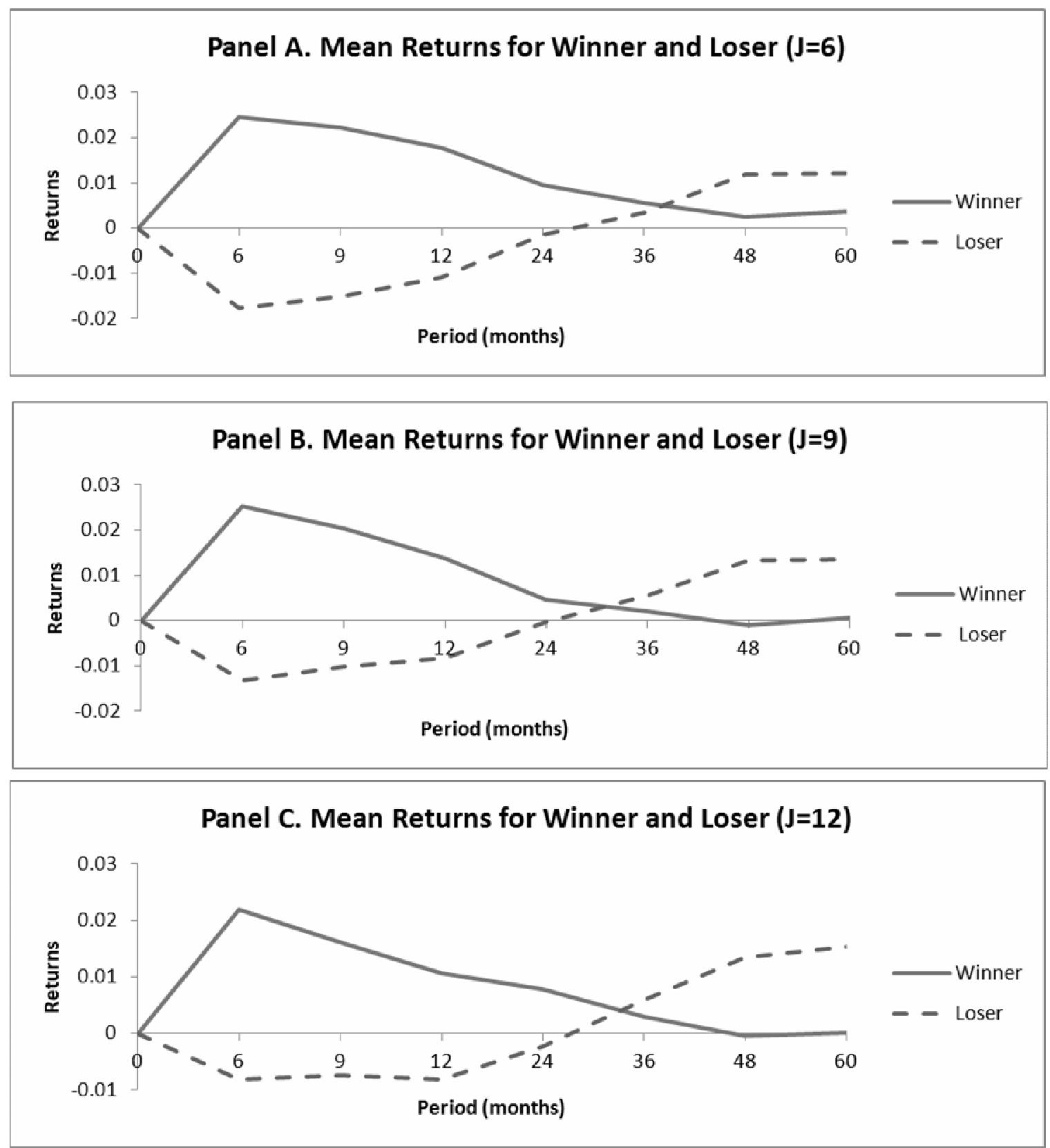

This figure presents average annualized returns for the Jegadeesh and Titman (1993) strategy: over a period of J months, I compute the deviations from UIP and find a loser and a winner currency. These two currencies are held for $\mathrm{K}$ months. The mean returns of the winner and loser currencies are illustrated bellow for $\mathrm{J}=6$ (Panel A), $\mathrm{J}=9$ (Panel B) and $\mathrm{J}=12$ (Panel C). 


\section{Chapter 3: Are FX trading returns compensation for risk?}

\section{Introduction}

Following the "forward puzzle", uncovered by Fama (1984), researchers and practitioners have advanced many strategies that create profits in the foreign exchange (FX) markets. The puzzle says that the forward exchange rates represent biased estimators of the future spot exchange rates. The unknown aspect in the abnormal returns obtained through the aforementioned strategies is whether they are just compensation for risk. This paper examines different measures of risk, based on the strategy developed in the second chapter.

The first essay of the present dissertation employs a strategy in the FX market, originally constructed for the stock market, which combines mean reversion and momentum. The results confirm the similarities between the two markets, which leads to the conclusion of a very high probability of finding the same risk factors in both markets. This supposition is in line with early studies that show similar empirical regularities in the FX and stock markets (Mussa, 1979).

The FX market gives researchers an important starting point for many strategies, such as moving average rules, contrarian, or carry trade, which are based on the same underlying puzzle as the strategy we employ. Hence, it makes sense to use in this paper the same risk factors as the ones reported in the literature. As Lustig and Verdelhan (2007) point out, just like in the equity markets, researchers should use diversified

portfolios in order to find if different factors are indeed measures of risk. They construct 
portfolios sorted on the interest rate differential, following the popular Fama - French (1993) procedure for the stock market. However, the present essay brings a unique perspective by using well diversified portfolios that are confirmed to behave similarly to equity portfolios.

Given that we use a procedure that could be easily implemented by practitioners, this paper resembles, to some extent, Villanueva's paper (2007). Villanueva (2007) investigates carry trade strategies for three currency-pairs and an equal-weighted carry trade, and examines market risk only for these time series returns. He finds that apart from some strategies involving the German Mark, market risk cannot explain abnormal returns produced by carry trades. Burnside et al. (2010) also investigate risk explanations in carry trades. They use a time-series analysis, as well as a Generalized Method of Moments (GMM) procedure for a panel analysis. ${ }^{14}$ In both approaches they find little evidence to support a risk-based explanation. Lustig and Verderlhan (2007) present a different side of the story, where an extended version of the Consumption Capital Asset Pricing Model (CCAPM) is shown to give significant results for the FX market.

We use time series regressions, the Fama-MacBeth (1973) two-pass approach and the GMM procedure for panel data to test the most popular asset pricing models found in the literature. For the GMM procedure, a few comments need to be made. First of all, we only report the results for the first stage estimation (and briefly, through a graph, the results of the second stage estimation). Cochrane (2005) notices that the first stage estimates are consistent and can be more robust from the economic and statistical point of

\footnotetext{
${ }^{14}$ The panel data analysis consists of payoffs for 1 or 5 carry trade portfolios and the 25 Fama - French portfolios.
} 
view. The second stage should improve the properties of estimators, but does not necessarily execute that properly. Rubio and Lozano (2010) notice that OLS and first stage GMM minimize pricing errors better than GLS and second stage GMM, but the first stage GMM does it better than OLS. Also, many researchers in the GMM literature find that the second stage GMM does not in fact bring anything new to the table compared to the first stage GMM. That is: the former does not improve efficiency compared to the latter (e.g. Arellano and Bond, 1991; Imbens, 2002). Following other papers (such as Fillat and Garduno, 2005), we only report the results of the first stage GMM estimation. Fillat and Garduno (2005) also notice that the asset pricing models are rejected too many times based on the $\mathbf{J}_{\mathrm{T}}$-test. Cochane (2005) notices the same problem (for instance, he finds that the well known Fama - French model is rejected formally by the $\mathrm{J}_{\mathrm{T}}$-test). Hence, the researcher should look also at other measures of fit, such as the $\mathrm{R}^{2}$ and resemblance between the predicted and the actual returns. Our paper takes these comments into consideration.

To begin with, we present the methodology and data in Section 2. Next, in Section 3, we review the literature on factors of risk in the FX market and test these theories in our new setup. In Section 4 we run robustness checks and, in the fifth and last section, we provide brief conclusions. 


\section{Methodology and Data}

\subsection{Combining Mean Reversion and Momentum Strategy}

The procedure that we use in this essay is a momentum - mean reversion combination for the FX market. This strategy was originally implemented for the stock market by Balvers and $\mathrm{Wu}$ (2006), but in the second chapter I find that it also gives significant returns for the FX market. It starts from the Uncovered Interest Parity (UIP) deviations of currency $i$ with respect to the US dollar, at time $t+1$, denoted as $y_{t+1}^{i}$ (which are different from zero according to Fama, 1984):

$y_{t+1}^{i}=s_{t+1}^{i}-f_{t}^{i}$,

where $s_{t+1}^{i}$ and $f_{t}^{i}$ are the log of the spot exchange rate and forward exchange rate, at time $t+1$ and $t$ respectively, both for currency $i$.

The strategy takes one third of the sample and runs the following pooled regression: ${ }^{15}$

$y_{t}^{i}=-\left(1-\delta^{i}\right)\left(x_{t-1}^{i}-\mu^{i}\right)+\sum_{j=1}^{J} \rho_{j}^{i}\left(x_{t-j}^{i}-x_{t-j-1}^{i}\right)+\varepsilon_{t}^{i}$,

where $x_{t}^{i}=\sum_{s=1}^{t} y_{s}^{i}, \mu^{i}$ is the average return, $J$ is the number of momentum lags, while $\delta$ and $\rho$ are the parameters to be estimated. As one can notice from equation (2), we can allow $\delta$ and $\rho$ to vary by country and/ or by lag. Intuitively, the first part of the equation represents the mean reversion component, while the second part is the momentum component.

\footnotetext{
${ }^{15}$ For more details on the procedure, see Balvers and $\mathrm{Wu}$ (2006) and the second chapter of the present dissertation paper.
} 
After running the pooled regression, the investor checks which currency has the highest expected return (Max) and which currency has the lowest expected return (Min). Then, she holds a long position on Max and a short position on Min for $K$ months. However, if all returns are positive, she only holds a long on Max. Conversely, if all returns are negative, she holds a short position on Min.

Then, the investor does the same thing for one third of the sample plus one month, updating the strategy one month at a time. The strategy is shown to give significant mean returns.

\subsection{Data}

The data set consists of the 1 month forward and spot exchange rates. Due to availability, the data come from two sources: for the period December 1978 - December 2001 from the Bank of International Settlements (BIS) database, and for January 2002 - February 2008 from Datastream. ${ }^{16}$ We collect monthly data for the Canadian dollar, German mark/ Euro, UK pound, and Japanese yen. The focus is on well-developed economies with liquid markets and easy implementation of currency speculation. The US dollar serves as the home currency.

Given that the strategy starts estimating mean returns based on the first third of the sample, and then progresses forward, we lose one third of the sample when obtaining returns on the portfolios. So, our analysis considers the period September 1989 -

\footnotetext{
${ }^{16}$ It took a few years after the collapse of the Bretton Woods System to establish a floating exchange system and for speculation to be possible. That is why most of the literature considers data on the FX market starting only around 1979.
} 
February 2008 for returns and risk factors. The monthly world market returns are obtained from the Morgan Stanley Capital International (MSCI) Barra. The risk-free rate is the one-month Treasury bill rate (from Ibbotson Associates), obtained from Kenneth French's website. In order to compute the growth rate of M1 per capita, we collect M1 data from the Board of Governors of the Federal Reserve System, and the population data from the U.S. Department of Commerce, Census Bureau. We take the Fama-French factors: SMB (Small Minus Big), HML (High Minus Low), and RM (market risk premium), from Kenneth French's website. The real per capita growth rates in nondurable consumption and net stock of durables are calculated using data from the U.S. Department of Commerce, Bureau of Economic Analysis. The nondurable consumption includes both nondurable goods and services. The durable stock of the representative consumer, denoted by $D_{t}$, is calculated as in Yogo (2006):

$D_{t}=(1-\delta) D_{t-1}+E_{t}$,

where $\delta$ is the depreciation rate and $E_{t}$ represents the units of durable consumption at time $t^{17}$

Table 3.1 presents descriptive statistics for our data. The highest mean return on the analyzed FX portfolios is $2.26 \%$ obtained for $K=1$ and $J=3$, while the lowest is $0.49 \%$ for $K=12$ and $J=6$. The standard deviation for the FX returns is much smaller (i.e. around $2 \%$ ), compared to that of the equity portfolios (i.e. around $3-4 \%$ ), represented by the world and U.S. market, HML, and SMB. As noted by Yogo (2006) and as intuitively expected the variation in the nondurable consumption growth is larger than that in the

\footnotetext{
${ }^{17} \delta$ is estimated by Yogo (2006) as around 6\% per quarter.
} 
durable stock growth. Panel B reports the correlations among the proposed risk factors. The largest coefficient is, as expected, between the world and the U.S. stock market $(87 \%)$.

\section{Sources of Risk}

The literature on the FX market suggests different explanations for the returns generated by the empirical failure of the UIP condition. Engel (1996) provides a comprehensive survey on models of risk premium in the FX literature. He offers explanations for two large branches of the literature: monetary explanations and consumption-based models. In the carry trade literature, given the similarities between the FX and equity markets, various authors (to be discussed later on) also test for the traditional Sharpe (1964) Lintner (1965) Capital Asset Pricing Model (CAPM), as well as for an Arbitrage Pricing Theory (Ross, 1976) model, such as the Fama-French (1993) three-factor model. Given that we deal with international markets, we also analyze the International CAPM of Solnik (1974a), Stulz (1981) and Adler and Dumas (1983). The goal of this paper is not to examine which model is the correct one from the theoretical point of view, but rather to test our model for documented risk factors.

The linear asset pricing models start from the following equation:

$$
E\left(y_{t}^{e i}\right)=\beta \lambda,
$$


where $y_{t}^{e i}$ is the excess return on asset $i$ at time $t, \lambda$ represents the mean risk premia, and the $\beta$ 's are the factor loadings. We test for $N$ portfolios and $L$ risk premia in equation (3.4).

In order to test this model, one should run the following regression:

$$
y_{t}^{e i}=\alpha+f_{t} \beta+\varepsilon_{t}^{i}
$$

where $f_{t}$ are the factors, and $\varepsilon_{t}^{i}$ are i.i.d. errors. The asset pricing model described in equation (3.4) assumes $\alpha$ to be zero.

Firstly, we take a sample of three arbitrarily chosen portfolios and test the models through a simple time series analysis. Secondly, given that the betas can vary over time, we follow a Fama-Macbeth (1973) two-pass approach and use all the portfolios resulting from different $(K, J)$ combinations. The third and last test uses a GMM approach. For this method, we construct a stochastic discount factor $m_{t}$ such that, by definition:

$$
E_{t}\left(y_{t+1}^{e i} m_{t+1}\right)=0
$$

The linear discount factor is of the following form:

$$
m_{t}=1-\left(f_{t}-\mu\right)^{\prime} b
$$

Note that equations (3.6) and (3.7) imply equation (3.4) if $\beta=\operatorname{cov}\left(y_{t}^{e i}, f_{t}\right) V_{f}^{-1}$ and $\lambda=V_{f} b$, with $V_{f}$ being the matrix of variance-covariance of the factors. Note that $\lambda$ represents the risk premia, while $b$ 's are the prices of risk. 
Following equation (3.6) and the law of iterated expectations, the imposed moment conditions imply that:

$$
E\left(y_{t}^{e i} m_{t}\right)=0
$$

We also enforce that:

$$
E\left(f_{t}\right)=\mu
$$

We have $L$ factors and this gives us $L$ parameters $b$ and $L$ parameters $\mu$ to estimate (i.e., a total of $2 L$ parameters). Equation (3.8) provides $N$ moment conditions, while (3.9) gives us $L$ moment conditions. In order to test whether the model is valid or not, we need an over-identification of the parameters. In this case, we require that: $2 L<N$ $+L$, or $L<N$. That is to say, we need a larger number of portfolios than of factors. GMM

tests the validity of the model. It uses a test statistic that follows a $\chi^{2}$ distribution with the number of degrees of freedom equal to the difference between the number of moment conditions and the number of parameters to be estimated (i.e., the number of overidentifications). Consequently, the number of degrees of freedom in this case equals to $N$ $-L$.

\subsection{CAPM, International CAPM and APT}

The similarities between the equity and FX markets give us the opportunity to employ the same asset pricing models that were originally created for and tested on the equity 
market. The use of an asset pricing model such as the CAPM in the FX market goes back to Sweeney (1986).

The CAPM, International CAPM and the APT were created for well-diversified portfolios, for which the non-systematic risk is eliminated. The portfolios that we consider in this paper are also well-diversified. Therefore, we can use these models to check for systematic sources of risk.

The CAPM considers that the only source of systematic risk is the market risk. The International CAPM also includes the currency risk. Ross's (1976) APT shows that one does not need to know which sources of risk exist in the market, but rather can use a certain number of well-diversified portfolios that mimic the actual risk factors. Fama and French (1993) create the well-known three "risk" factors that prove to be good fits for the US equity market.

The literature on the FX market usually rejects these explanations of the abnormal returns as rewards for systematic risk. Sweeney (1986) investigates the traditional CAPM for trading rule strategies and finds that the market beta is not significant. Neely et al. (1997) manufacture a trading rule through a genetic algorithm and find that the world and country risk factors are significant only in two cases (and in one of them, the beta bears the wrong sign). Burnside et al. (2010) consider linear models and employ factors such as the market risk premium, Fama - French (1993), consumption and extended consumption factors. Again, they do not obtain significant results.

The CAPM shows that the expected gross excess return on asset $i$ at time $t$ can be written as: 
$E\left(R_{t}^{i}-R_{t}^{f}\right)=b_{1} \operatorname{cov}\left(r_{t}^{w}, R_{t}^{i}-R_{t}^{f}\right)$,

where $r_{t}^{w}$ is the world market excess return.

This translates to:

$E\left(R_{t}^{i}-R_{t}^{f}\right)=\beta_{1} E\left(r_{t}^{w}\right)$

which, similar to equation (3.5), can be written as:

$y_{t}^{e i}=\alpha+\beta_{1} r_{t}^{w}+\varepsilon_{t}^{i}$

Table 3.2 reports time series regression outcomes for three arbitrarily chosen portfolios (out of the twenty possible combinations of $K$ and $J$ ): $K=1, J=6 ; K=6, J=3$; $K=12, J=6$. Both CAPM and Fama-French factors have insignificant $\beta$ coefficients. The International CAPM gives some statistically significant coefficients. One critique of this simple time series regression is that the beta coefficients can vary over time.

Table 3.3 reports the results of a simplified Fama - MacBeth (1973) approach, as described by Cochrane (2005). We first run a time series regression for each of the twenty portfolios. Then, we use the $\beta$ coefficients as the independent variables in a second series of regressions, this time cross-sectionally. The coefficients obtained through the second set of regressions should be equal, on average, to the mean risk premia. The first column in Table 3.3 reports the GRS (Gibbons-Ross-Shanken) test. In all three models we can reject the null hypothesis that the intercepts are jointly equal to zero. For the second pass, we report the $t$-statistics, and also the Shanken corrected $t$ statistics. The Fama - MacBeth standard errors are not corrected for the fact that in the 
second pass we use the betas estimated through the first pass. Nevertheless, the Shanken correction solves this problem. For the CAPM, the coefficient is statistically different from zero only at the $10 \%$ significance level and it is negative. This motivates us to state that the market risk factor is not enough to explain the FX returns. The Fama-French model provides statistically different from zero coefficients for the market and for SMB. However, they are, again, negative. Similar results are obtained for the International CAPM. The second pass $\mathrm{R}^{2}$ is best for the Fama-French model (compare 27\% with a 9\% $\mathrm{R}^{2}$ for the CAPM).

Table 3.4 shows the results for the GMM approach. The coefficients for the CAPM are statistically different from zero and yet, the $J_{T}$-test gives us a rejection of the null hypothesis. This means that the market factor by itself fails to explain the excess returns. Conversely, the Fama-French model and the International CAPM provide a completely different picture: the models are still rejected, but most of the coefficients are not precisely estimated. We also report the $\mathrm{R}^{2}$ for the models, calculated as:

$$
R^{2}=1-\frac{(\bar{y}-\hat{y})(\bar{y}-\hat{y})}{(\bar{y}-\tilde{y})(\bar{y}-\tilde{y})},
$$

where $\bar{y}$ is the actual mean excess return on the portfolios, $\hat{y}$ is the estimated mean return, and $\tilde{y}$ is the average across all portfolios. The results show an $\mathrm{R}^{2}$ of $7 \%$ for the CAPM and above $80 \%$ for the other two analyzed models. ${ }^{18}$

\footnotetext{
${ }^{18}$ When computing the $\mathrm{R}^{2}$ for the second stage GMM (not reported), they are all negative, which is in line with Burnside et al. (2010).
} 


\subsection{Monetary Explanations}

These approaches start from the general equilibrium model described by Lucas (1978). The first proponents of these explanations for the currency risk premium are Hodrick and Srivastava (1986). They develop a two-country setting where individuals need foreign currency (provided by their own governments) in order to purchase goods produced in the other country. Hence, money shocks have an influence on consumption either through the cash-in-advance constraints, or money as a store of value in the overlapping generations model (Engel, 1996). The monetary policy models have the advantage of being able to use time-varying risk premia. Even if the role of monetary policy has been well documented in theoretical papers, the literature on carry trades did not find much significance explaining abnormal returns (Burnside et al., 2010; Hollifield and Yaron, 2001).

The influence of the monetary policy in the FX market can also be found in a separate branch of the literature that examines the relationship between market inefficiency and Central Bank intervention. Szakmary and Mathur (1997) show that central bank interventions are correlated with the profitability of returns generated by moving average rules for three major currencies. However, Neely (2002) supports the conjecture that the intervention is not the cause for the FX market inefficiency.

We consider the growth rate of M1 per capita as the monetary factor. ${ }^{19}$ The time series regressions in Table 3.2 provide a unified picture of a statistically significant intercept and statistically insignificant factor loadings. The model fails to explain the FX

\footnotetext{
${ }^{19} \mathrm{We}$ also check other factors (i.e. federal funds rate, liquidity premium, term spread, and VXO), but the results, not reported in this paper, are very similar to what we obtain for M1.
} 
returns. The two-pass approach in Table 3.3 shows that the intercepts are different from zero in the first pass. The second pass intercept is also statistically different from zero, while the other coefficients are statistically zero. This is consistent with the results in Table 3.4, that show rejection of the monetary model based on the $\mathrm{J}_{\mathrm{T}}-$ test. $\mathrm{R}^{2}$ is actually pretty good in the first stage GMM estimation (89\%).

\subsection{Consumption-Based Models}

The more controversial part of the literature on risk factors in the FX market is dedicated to the Consumption CAPM (CCAPM), originally derived by Lucas (1978) and Breeden (1979). A newer version of the model, proposed by Yogo (2006), introduces in the equation the nondurable consumption, durable stock, and the market risk. Without stating that this is the only extended version of the CCAPM found in the literature, we will only consider this one.

Mark (1985) is the first to implement the CCAPM in the FX market, but he rejects the model. However, a follow-up by Hodrick (1989) for UK data does not reject the model. The rest of the literature gives contrasting results.

Lustig and Verdelhan (2007) use consumption-based pricing factors and show that the model explains up to $80 \%$ of the variation in the returns on their portfolios (constructed similarly to the Fama-French portfolios, but sorted by interest rates). The apparent success of the model is intuitively appealing: when the US business cycle decelerates, causing US consumption to decrease, the US investor who holds highyielding currencies would further decrease her consumption. Therefore, low interest rate 
currencies provide a hedge against slowdown in domestic consumption, while high interest rate currencies systematically expose the investor to more domestic consumption risk. Figure 3.1 shows how the stock of durables and consumption of nondurables behave over the analyzed time period. It is obvious that they are correlated with periods of recession/ economic growth. The Lustig and Verdelhan (2007) procedure was critiqued by Burnside (2007), who blames the weakness of the statistical identification. De Santis and Fornari (2008) use an extended dataset and a slightly different statistical method, and show that most durable consumption factors give significant coefficients, while nondurables only occasionally. Burnside at al. (2010) cannot get any significance of the CCAPM or Yogo's (2006) Extended CCAPM for carry trade returns. However, all these papers use quarterly data. This paper uses monthly data, offering a different perspective on the issue.

Yogo's (2006) Extended CCAPM writes the expected gross excess return on asset $i$ at time $t$, as:

$E\left(y_{t}^{e i}\right)=b_{1} \operatorname{cov}\left(\Delta c_{t}, y_{t}^{e i}\right)+b_{2} \operatorname{cov}\left(\Delta d_{t}, y_{t}^{e i}\right)+b_{3} \operatorname{cov}\left(r_{t}^{m}, y_{t}^{e i}\right)$,

where $\Delta c_{t}$ is the change in nondurable consumption, $\Delta d_{t}$ is the change in durable stock, and $r_{t}^{m}$ is the market excess return; $b_{1}, b_{2}$ and $b_{3}$ are the prices of risk.

This gives the following linear model:

$E\left(y_{t}^{e i}\right)=\beta_{1} E\left(\Delta c_{t}\right)+\beta_{2} E\left(\Delta d_{t}\right)+\beta_{3} E\left(r_{t}^{m}\right)$,

Or, the following regression: 
$y_{t}^{e i}=\alpha+\beta_{1} \Delta c_{t}+\beta_{2} \Delta d_{t}+\beta_{3} r_{t}^{m}+\varepsilon_{t}^{i}$,

The traditional CCAPM assumes $\beta_{2}=0$, while the CAPM assumes $\beta_{1}=\beta_{2}=0$. The model predicts that a high $\beta_{1}$ or $\beta_{2}$ gives higher expected returns. All models predict that $\alpha=0$.

The time series regressions in Table 3.2 show a positive $\alpha$ and insignificant factor loadings. Table 3.3 does not show more significance. However, the reader should notice that among all analyzed models, the extended CCAPM gives the highest $\mathrm{R}^{2}$ of $32 \%$. The GMM test though shows a completely different picture. Even though both models are rejected by the $J_{T}$-test in Table 3.4, CCAPM and Extended CCAPM exhibit most of their coefficients statistically significant. Moreover, their $\mathrm{R}^{2}$ are very high in the first stage GMM (over 96\%) and, for the traditional CCAPM, the $\mathrm{R}^{2}$ is the only positive (and reasonably high) $\mathrm{R}^{2}$ among all the analyzed models in the second stage GMM (not reported in the table). That can raise some important questions. Is in fact the CCAPM the best model that can explain FX returns? As shown in the introduction, the literature on the GMM procedure shows that sometimes the second stage results in the GMM procedure (and consequently the $J_{T}$-test) are not very reliable. They conclude that one can only look at the first stage. And in our case, the first stage shows statistically significant coefficients. We conclude that the CCAPM is the only model that can explain reasonably well the FX returns. We further analyze this statement below. 


\subsection{Model Comparison}

These results agree with Lustig and Verdelhan (2007) and somewhat contradict Burnside (2007). In order to represent our results graphically, we compute the estimated excess returns, derived from equations (3.7) and (3.9) as:

$E\left(y_{t}^{e i}\right)=E\left[y_{t}^{e i}\left(f_{t}-\mu\right)^{\prime} b\right]$,

Figures 3.2 and 3.3 present for the first and second stage GMM respectively the mean estimated excess returns on the twenty portfolios, on the horizontal axis, and the actual mean excess returns on the vertical axis. The red line is the $45^{0}$ line. All points should be very close to the red line if the excess returns were a compensation for risk. Following the first stage estimation, it is obvious that the CCAPM and its extension are the best fitted models. One can see how the predicted values of the analyzed returns are very close to the actual values. The second stage estimation shows that only the CCAPM provides a good estimation of what the excess returns should be (as expected from the positive and fairly large $\mathrm{R}^{2}$ ). The rejection of the model with the traditional $J_{T}$-test is probably due to the poor estimation of the spectral density matrix.

However, when comparing asset pricing models, as Lewellen et al. (2010) note, one cannot simply look at the measures of cross-sectional fit. If the analyzed portfolios have a strong factor structure, the pricing errors are idiosyncratic and probably not correlated with the factors of the asset pricing model. Consequently, the model betas and the "true" betas are linearly correlated, leading to, for instance, a high $\mathrm{R}^{2}$. Table 3.5 presents the $\mathrm{R}^{2}$, and $\mathrm{J}_{\mathrm{T}}$ - tests for the first-stage GMM estimation. As one can notice, the $\mathrm{R}^{2 \text { s }}$ are very large for some models, reaching $96 \%$ and $99 \%$ for the CCAPM and 
Extended CCAPM, respectively. This can lead us again to the conclusion that the CCAPM and its extension are the best models to explain FX returns. However, according to Lewellen et al. (2010), a high $\mathrm{R}^{2}$ does not necessarily mean that we found the "true" model. Comparing different asset pricing models with a different number of factors is not as easy as just comparing measures of fit for these models. They give multiple solutions to this problem.

The first is to include other portfolios into the test. We add the 25 Fama-French portfolios sorted by size and value (obtained from Kenneth French's website). These portfolios are known to be explained in large proportion by the Fama-French factors. Table 3.5 provides the measures of fit. None of the models is valid according to the $J_{T^{-}}$ test, but the first stage $\mathrm{R}^{2}$ continues to be very high for the extended and traditional CCAPM, showing that these are indeed models that could explain the FX returns, as predicted by Lustig and Verdelhan (2007).

In Figure 3.4, the blue stars represent the $20 \mathrm{FX}$ portfolios, while the green bubbles symbolize the 25 Fama-French portfolios. Interestingly again, the extended CCAPM shows the best fit for the FX returns, even if the $J_{T}$-test shows rejection of the model.

A second solution for the problems reported by Lewellen et al. (2010) is to check whether the cross-sectional slopes and the intercept have an economical significance. We already addressed this issue in Table 3.3. Only the CCAPM and its extension do a good job from this point of view. 
The third solution considers confidence intervals (C.I.) for the measures of fit instead of only point estimates. As Lewellen et al. (2010) suggest, authors only look at rejecting or accepting the null, without paying too much attention to how powerful their tests really are. A C.I. shows the range of the "true" parameters consistent with the data. We compute the $90 \%$ C.I. for the first and second stage $\mathrm{R}^{2}$ and $J_{T}$-test, obtained in 1,000 draws of multivariate normally distributed factors. The results are reported in Table 3.5. The CCAPM and its analyzed extension have $\mathrm{R}^{2}$ s above the higher limit of the C.I., giving them an edge over the other models. Some of the other models (i.e. the CAPM, International CAPM and Fama-French) actually do more poorly than a random choice of factors when it comes to actually explaining the variation in the returns. However, the $J_{T^{-}}$ test shows the opposite picture. The models that performed well from the $\mathrm{R}^{2}$ point of view have very high pricing errors (the $J_{T}$-test is above the higher end of the C.I.). There is one exception to this rule: the extended CCAPM performs relatively well from this point of view as well. We can safely conclude that Yogo's extension of the CCAPM is indeed the best model.

\section{Robustness Checks}

In January 1999, the FX market changed drastically with the introduction of the Euro and the demise of currencies that were playing a very important role up to that point in time. Table 3.5 provides GMM results from the first-stage estimation, for two subperiods: prior to January 1999 and after January 1999. The results are not different for the 
two sub-periods, compared to the whole period considered in Table 3.4. Again, the only model that keeps its very high $\mathrm{R}^{2}$ for both periods is the extended.

\section{Conclusions and Future Research}

The literature has documented different explanations for the profitability of strategies in the FX market. One of them is the presence of a "peso" problem, particularly appealing to carry trade researchers. Burnside et al. (2010) explain that carry trade positive returns might materialize due to the fact that the rare event of a large appreciation of the foreign currency just does not happen. They find evidence in this regard, rejecting the possibility of a second explanation, that these returns are simply a compensation for bearing risk.

The appropriate measures of risk are a different side of the story. The theoretical background for the sources of risk in the FX market is weak. The only intuitive approaches come from the equity markets, or from the consumption-based models.

We take these issues and give them a new spin. The trading strategy that we use resembles slightly the carry trades, but it is in fact very different from any other strategy in the FX market and more similar to strategies employed in the stock market. Is it possible that these returns are due to the "peso" problems? Since this strategy behaves similarly in the stock and FX markets, we can only assume that the reasons for obtaining the abnormal returns are the same for the two markets. Hence, the only plausible explanation besides the market inefficiency is the compensation for risk. 
We find that the APT, International CAPM and monetary models do a poor job in explaining these returns. However, the Yogo's extension of the CCAPM does a pretty good job in explaining these returns. To the best of our knowledge, this study is the most comprehensive in the literature and, given our returns' resemblance to the equity returns, can shed a new light on what asset pricing models can, or cannot be used in the FX market.

As a future extension of this essay, we would also like to pursue how many factors should be considered for the FX returns, based on a Principal Components Analysis, as in Lewellen et al. (2010). We would also like to take into consideration other factors that could be considered sources of risk, such as those in the hedge funds literature. 
Table 3.1. Descriptive Statistics

Panel A: FX Returns

\begin{tabular}{|c|c|c|c|c|c|c|c|c|c|c|c|c|c|c|c|c|c|c|c|c|}
\hline \multirow{2}{*}{$\frac{\mathbf{K}}{\mathbf{J}}$} & \multicolumn{4}{|c|}{1} & \multicolumn{4}{|c|}{3} & \multicolumn{4}{|c|}{6} & \multicolumn{4}{|c|}{9} & \multicolumn{4}{|c|}{12} \\
\hline & 3 & 6 & 9 & 12 & 3 & 6 & 9 & 12 & 3 & 6 & 9 & 12 & 3 & 6 & 9 & 12 & 3 & 6 & 9 & 12 \\
\hline Mean (\%) & 2.26 & 1.27 & 0.77 & 0.53 & 1.67 & 1.35 & 0.98 & 0.66 & 1.02 & 1.15 & 1.01 & 0.71 & 0.73 & 0.70 & 0.80 & 0.67 & 0.63 & 0.49 & 0.54 & 0.58 \\
\hline St. Dev. (\%) & 2.46 & 2.61 & 2.93 & 2.88 & 2.16 & 2.39 & 2.67 & 2.66 & 1.75 & 2.15 & 2.41 & 2.52 & 1.57 & 1.88 & 2.20 & 2.31 & 1.53 & 1.73 & 1.93 & 2.07 \\
\hline
\end{tabular}

\section{Panel B: Risk Factors}

\begin{tabular}{|c|c|c|c|c|c|c|c|c|c|c|c|c|}
\hline & \multirow{2}{*}{$\begin{array}{c}\text { Mean } \\
(\%)\end{array}$} & \multirow{2}{*}{$\begin{array}{c}\text { St. Dev. } \\
(\%)\end{array}$} & \multicolumn{10}{|c|}{ Correlation Coefficients } \\
\hline & & & $\mathbf{R W}$ & RCCGN & RCCGD & M1CG & RRM & RSMB & RHML & DUIPJY & DUIPBP & DUIPGM \\
\hline RW & 0.28 & 4.01 & 1 & & & & & & & & & \\
\hline RCCGN & 0.14 & 0.35 & 0.22 & 1 & & & & & & & & \\
\hline RCCGD & 0.38 & 0.17 & -0.03 & 0.17 & 1 & & & & & & & \\
\hline M1CG & 0.17 & 0.67 & -0.09 & -0.17 & -0.26 & 1 & & & & & & \\
\hline RRM & 0.53 & 4.05 & 0.87 & 0.26 & -0.06 & -0.04 & 1 & & & & & \\
\hline RSMB & 0.11 & 3.55 & 0.10 & 0.15 & 0.09 & 0.00 & 0.22 & 1 & & & & \\
\hline RHML & 0.32 & 3.25 & -0.36 & -0.15 & 0.01 & 0.05 & -0.49 & -0.43 & 1 & & & \\
\hline DUIPJY & 0.13 & 2.70 & -0.14 & 0.07 & 0.11 & -0.19 & -0.04 & 0.05 & 0.07 & 1 & & \\
\hline DUIPBP & -0.27 & 2.26 & -0.13 & 0.05 & 0.04 & -0.05 & -0.01 & 0.18 & 0.02 & 0.32 & 1 & \\
\hline DUIPGM & -0.17 & 2.48 & -0.06 & 0.05 & 0.11 & -0.13 & 0.03 & 0.07 & 0.06 & 0.48 & 0.72 & 1 \\
\hline
\end{tabular}

Panel A reports the means and the standard deviations for the excess returns on portfolios constructed according to the procedure described in section 2.1. $K$ is the holding period and $J$ is the number of momentum lags. Panel B reports descriptive statistics for the risk factors: the world excess return, the growth rate of real consumption of nondurables per capita, the growth rate of real net stock of durables per capita, the growth rate of M1 per capita, real US market excess return, SMB, and HML, and the deviations from UIP for the Japanese yen, British pound and German mark. The analysis period is 1989:09-2008:02. 
Table 3.2. Time Series Regressions

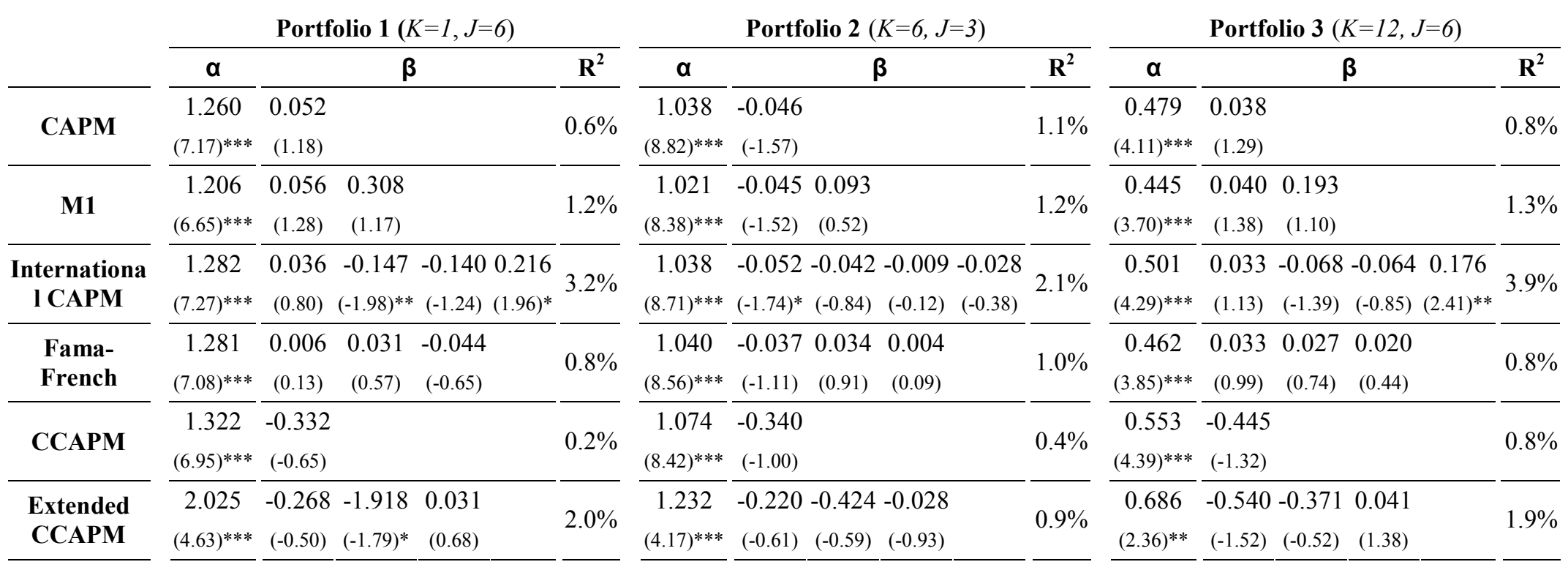

We run the following time series regression for three arbitrarily chosen FX portfolios, constructed according to the procedure described in section 2.1: $y_{1} t^{t} e i=a+f_{1} t\left(+E_{1} t^{t_{i}}\right.$. The CAPM considers the world excess return as the only risk factor. The second model takes world excess return and M1 as the sources of risk. The International CAPM introduces the currency risk to the classic CAPM. The Fama-French model assumes that there are three risk factors: US market excess return, SMB, and HML (in this order). The CCAPM has the growth rate of real per capita consumption of nondurables as the only risk premium. The Extended CCAPM takes into consideration, besides the CCAPM factor, the growth rate of real per capita net stock of durables, and the US market excess return. For each coefficient, $t$-stats are reported between round brackets (one, two or three asterisks denote significance levels of $10 \%, 5 \%$ and $1 \%$, respectively). 


\section{Table 3.3. Two-Pass Approach}

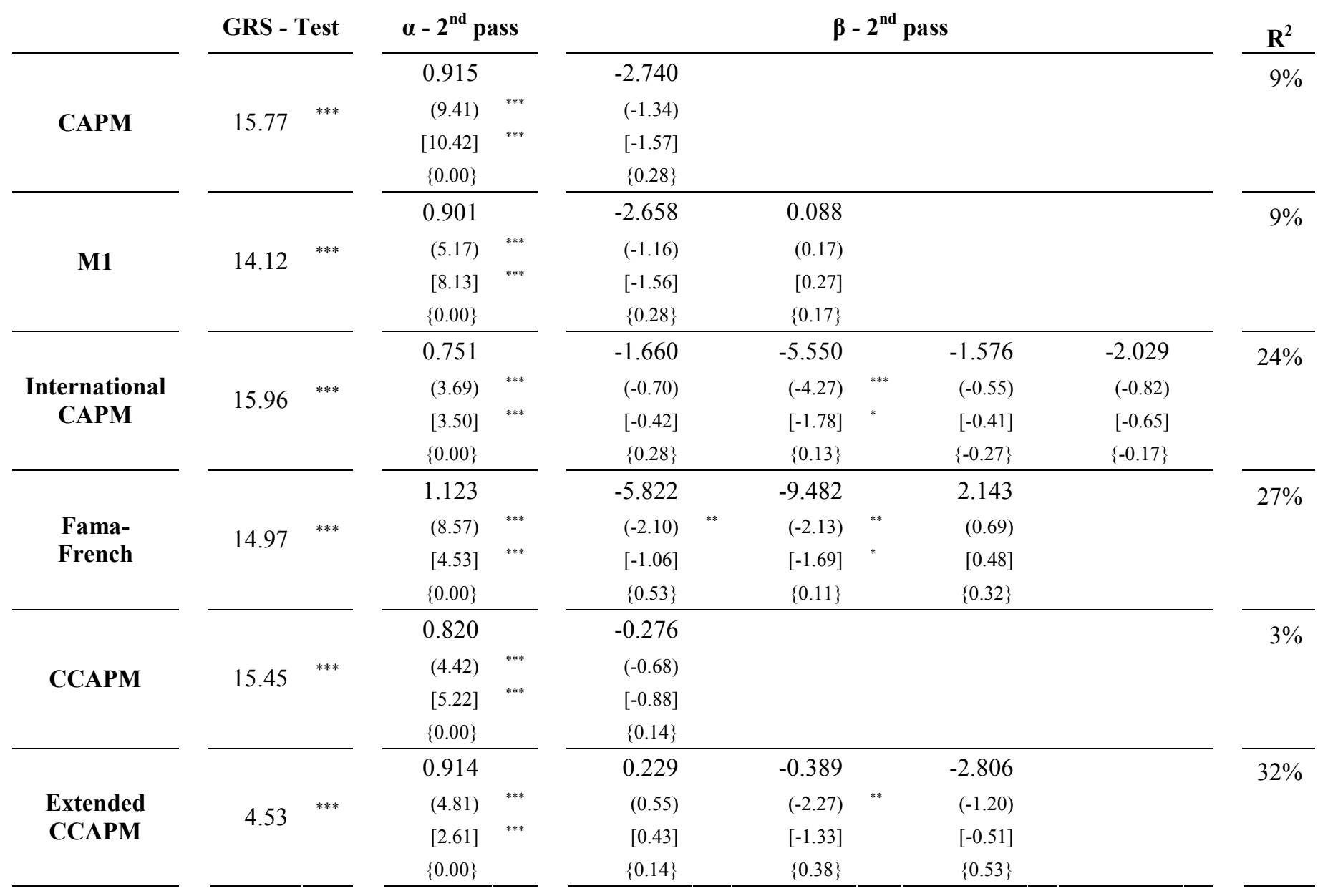

This table reports the results for the Fama-MacBeth (1973) two-pass approach procedure. We use the FX portfolios constructed through the procedure described in section 2.1. The CAPM considers the world excess return as the only risk factor. The second model takes world excess return and M1 as the sources of risk. The International CAPM introduces the currency risk to the classic CAPM. The Fama-French model assumes that there are three risk factors: US market excess return, SMB, and HML (in this order). The CCAPM has the growth rate of real per capita consumption of nondurables as the only risk premium. The Extended CCAPM takes into consideration, besides the CCAPM factor, the growth rate of real per capita net stock of durables, and the US market excess return. The GRS-test checks the null hypothesis of jointly zero intercepts from the first pass. The rest of the columns report the coefficients obtained in the second pass. $T$-stats are between round brackets, Shanken adjusted $t$-stats - between square brackets, and the realized mean risk premia - between curly brackets. One, two or three asterisks for the $t$-stats denote significance levels of $10 \%, 5 \%$ and $1 \%$, respectively. 
Table 3.4. GMM Approach

\begin{tabular}{l}
\hline CAPM \\
\hline RM
\end{tabular}

M1

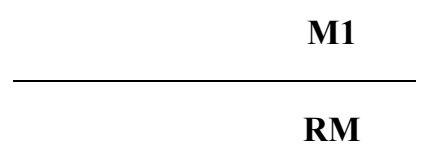

\begin{tabular}{|c|c|c|c|c|c|}
\hline $\boldsymbol{\mu}$ & \multicolumn{3}{|c|}{ b } & $\mathbf{R}^{2}$ & $\mathbf{J}_{\mathrm{T}^{-}}$Test \\
\hline 1.837 & & -0.495 & & 70 & 72.829 \\
\hline$(-2.98)$ & *** & (4.77) & $* * *$ & 170 & {$[0.00]$} \\
\hline 0.899 & & 0.313 & & & \\
\hline$(-1.69)$ & $*$ & (2.60) & $* * *$ & $89 \%$ & 94.373 \\
\hline-1.572 & & -0.077 & & & {$[0.00]$} \\
\hline$(0.96)$ & & $(0.67)$ & & & \\
\hline 0.217 & & -0.522 & & & \\
\hline (1.24) & & $(-0.38)$ & & & \\
\hline
\end{tabular}

$\begin{array}{cc}\underset{\text { International }}{\text { CAPM }} & \text { DuipJY } \\ & \text { DuipBP } \\ & \\ & \text { DuipGM }\end{array}$

0.243

$(2.19)^{* *} \quad(-2.67)$

$-0.233$

0.101

$(-2.89)$

***

1.095

$-0.860$

(0.69)

\begin{tabular}{rr}
$(-0.97)$ & $(0.13)$ \\
\hline 0.285 & -0.326 \\
$(1.04)$ & $(0.99)$ \\
-0.293 & 0.351
\end{tabular}

\begin{tabular}{cc}
$\begin{array}{c}\text { Fama- } \\
\text { French }\end{array}$ & SMB \\
& HML \\
\hline CCAPM & \\
\hline
\end{tabular}

\begin{tabular}{lc}
\hline & ND \\
Extended & D \\
CCAPM & \\
& RM \\
\hline
\end{tabular}

$-0.293$

$(-1.35)$

0.351

(1.55)

$81 \%$

82.137

0.619

0.883

\begin{tabular}{c}
$(-0.96)$ \\
\hline-0.27
\end{tabular}

\begin{tabular}{rrrrrr}
$(-1.70)$ & $*$ & $(2.62)$ & $* * *$ & $96 \%$ & {$[0.00]$} \\
\hline 0.193 & & 0.148 & & & \\
$(8.64)$ & & $(-1.26)$ & & & \\
0.528 & & -0.909 & & $99 \%$ & 94.262 \\
$(2.01)$ & & $(3.03)$ & & & \\
4.213 & & 0.026 & & & \\
$(1.99)$ & & & \\
\hline
\end{tabular}

We construct an SDF $m_{t}$ and use the following moment conditions: $E\left(y_{t}^{e i} m_{t}\right)=0$ (where $y_{t}^{e i}$ is the excess return on the FX portfolios constructed through the procedure described in section 2.1 and $m_{t}=1-\left(f_{t}-\mu\right)^{\prime} b$, with $E\left(f_{t}\right)=\mu$. We estimate parameters $\mu$ and $b$. This table reports the first-stage estimation, which assumes the weighting matrix to be equal to the identity matrix. The $J_{T}$-test checks the validity of the model. The CAPM considers the world excess return as the only risk factor. The second model takes world excess return and M1 as the sources of risk. The International CAPM introduces the currency risk to the classic CAPM. The Fama-French model assumes that there are three risk factors: US market excess return, SMB, and HML (in this order). The CCAPM has the growth rate of real per capita consumption of nondurables as the only risk premium. The Extended CCAPM takes into consideration, besides the CCAPM factor, the growth rate of real per capita net stock of durables, and the US market excess return. $T$-stats are between round brackets (one, two or three asterisks denote significance levels of $10 \%, 5 \%$ and $1 \%$, respectively), while $p$-values for the $J_{T}$-test are between square brackets. The $\mathrm{R}^{2}$ is also reported. 
Table 3.5. Models Comparison

\begin{tabular}{|c|c|c|c|c|c|}
\hline & & $\mathbf{R}^{2}$ - first stage & $\begin{array}{c}\mathbf{J}_{\mathrm{T}} \text {-test - second } \\
\text { stage }\end{array}$ & $\begin{array}{c}R^{2} \text { - second } \\
\text { stage }\end{array}$ & $\begin{array}{c}\mathbf{J}_{\mathrm{T}} \text {-test - first } \\
\text { stage }\end{array}$ \\
\hline \multirow{4}{*}{ CAPM } & \multirow{2}{*}{ FX only } & 0.07 & 72.83 & -2.36 & 60.53 \\
\hline & & {$[0.84 ; 0.86]$} & {$[103.81 ; 108.13]$} & {$[-0.77 ;-0.67]$} & {$[175.21 ; 184.81]$} \\
\hline & \multirow{2}{*}{$\begin{array}{l}\text { FX and } \\
25 F F\end{array}$} & 0.98 & 265.18 & 0.17 & 597.49 \\
\hline & & {$[0.73 ; 0.75]$} & {$[483.55 ; 499.41]$} & {$[-2.11 ;-1.94]$} & $\begin{array}{c}{[1,063.87 ;} \\
1,110.00] \\
\end{array}$ \\
\hline \multirow{4}{*}{ M1 } & \multirow{2}{*}{ FX only } & 0.89 & 94.37 & -0.34 & 180.23 \\
\hline & & {$[0.90 ; 0.91]$} & {$[81.48 ; 84.91]$} & {$[-1.00 ;-0.91]$} & {$[70.05 ; 74.15]$} \\
\hline & \multirow{2}{*}{$\begin{array}{l}\text { FX and } \\
25 F F\end{array}$} & 0.87 & 709.32 & -4.00 & 312.09 \\
\hline & & {$[0.83 ; 0.84]$} & {$[433.09 ; 447.44]$} & {$[-1.42 ;-1.32]$} & {$[377.13 ; 396.70]$} \\
\hline \multirow{4}{*}{$\begin{array}{c}\text { International } \\
\text { CAPM }\end{array}$} & \multirow{2}{*}{ FX only } & 0.87 & 40.52 & -2.27 & 17.02 \\
\hline & & {$[0.95 ; 0.95]$} & {$[52.80 ; 55.29]$} & {$[-1.12 ;-1.03]$} & {$[33.15 ; 34.53]$} \\
\hline & \multirow{2}{*}{$\begin{array}{l}\text { FX and } \\
25 F F\end{array}$} & 0.76 & 261.99 & -3.89 & 137.64 \\
\hline & & {$[0.89 ; 0.89]$} & {$[353.16 ; 364.88]$} & {$[-1.38 ;-1.27]$} & {$[211.59 ; 219.60]$} \\
\hline \multirow{4}{*}{$\begin{array}{l}\text { Fama- } \\
\text { French }\end{array}$} & \multirow{2}{*}{ FX only } & 0.81 & 82.14 & -2.20 & 19.33 \\
\hline & & {$[0.93 ; 0.93]$} & {$[66.27 ; 69.42]$} & {$[-1.09 ;-1.00]$} & {$[45.99 ; 48.16]$} \\
\hline & \multirow{2}{*}{$\begin{array}{l}\text { FX and } \\
25 F F\end{array}$} & -1.02 & 653.18 & -2.61 & 709.91 \\
\hline & & {$[0.86 ; 0.87]$} & {$[392.35 ; 404.92]$} & {$[-1.42 ;-1.32]$} & {$[273.10 ; 285.43]$} \\
\hline \multirow{4}{*}{ CСАРM } & \multirow{2}{*}{ FX only } & 0.96 & 92.03 & 0.68 & 348.97 \\
\hline & & {$[0.84 ; 0.86]$} & {$[103.81 ; 108.13]$} & {$[-0.77 ;-0.67]$} & {$[175.21 ; 184.81]$} \\
\hline & \multirow{2}{*}{$\begin{array}{l}\text { FX and } \\
25 F F\end{array}$} & 0.68 & 340.07 & -9.57 & 2515.52 \\
\hline & & {$[0.86 ; 0.87]$} & {$[392.35 ; 404.92]$} & {$[-2.11 ;-1.94]$} & $\begin{array}{c}{[1,063.87 ;} \\
1,110.00]\end{array}$ \\
\hline \multirow{4}{*}{$\begin{array}{l}\text { Extended } \\
\text { CCAPM }\end{array}$} & \multirow{2}{*}{ FX only } & 0.99 & 94.26 & -0.85 & 48.51 \\
\hline & & {$[0.93 ; 0.93]$} & {$[66.27 ; 69.42]$} & {$[-1.09 ;-1.00]$} & {$[45.99 ; 48.16]$} \\
\hline & FX and & 0.97 & 257.48 & 0.08 & 545.34 \\
\hline & 25FF & {$[0.73 ; 0.75]$} & {$[483.55 ; 499.41]$} & {$[-1.42 ;-1.32]$} & {$[273.10 ; 285.43]$} \\
\hline
\end{tabular}

This table reports the comparison between the analyzed models. The CAPM considers the world excess return as the only risk factor. The second model takes world excess return and M1 as the sources of risk. The International CAPM introduces the currency risk to the classic CAPM. The Fama-French model assumes that there are three risk factors: US market excess return, SMB, and HML (in this order). The CCAPM has the growth rate of real per capita consumption of nondurables as the only risk premium. The Extended CCAPM takes into consideration, besides the CCAPM factor, the growth rate of real per capita net stock of durables, and the US market excess return. We study excess return on the FX portfolios constructed through the procedure described in section 2.1 and the Fama-French 25 portfolios sorted on size and value. We report the $\mathrm{R}^{2}$ for the first and second stage GMM estimation, as well as the $J_{T}$-test and its p-value. The $90 \%$ C.I. (between square brackets) are obtained from 1,000 draws of multivariate normal random factors. 
Table 3.6. GMM First Stage - Sub-periods

1989:09 - 1998:12

\begin{tabular}{|c|c|c|c|c|c|c|c|}
\hline CAPM & & -1.653 & & 0.438 & & $5 \%$ & 138.529 \\
\hline \multirow{5}{*}{ M1 } & \multirow{3}{*}{$\mathbf{R M}$} & & & & & \multirow{5}{*}{$94 \%$} & \\
\hline & & -0.326 & & 1.703 & & & \\
\hline & & $(-1.80)$ & * & $(3.98)$ & *** & & 101.919 \\
\hline & \multirow{2}{*}{ M1 } & 0.418 & & 0.111 & & & {$[0.00]$} \\
\hline & & $(1.27)$ & & $(1.08)$ & & & \\
\hline \multirow{8}{*}{$\begin{array}{c}\text { International } \\
\text { CAPM }\end{array}$} & \multirow{2}{*}{$\mathbf{R M}$} & 0.182 & & 0.332 & \multirow{8}{*}{$* * *$} & \multirow{8}{*}{$84 \%$} & \\
\hline & & $(0.51)$ & & $(1.21)$ & & & \\
\hline & \multirow{2}{*}{ DuipJY } & -0.801 & & 1.023 & & & \\
\hline & & $(-1.88)$ & * & $(4.45)$ & & & 51.611 \\
\hline & \multirow{2}{*}{ DuipBP } & -0.051 & & -0.302 & & & {$[0.00]$} \\
\hline & & $(-0.17)$ & & $(-0.53)$ & & & \\
\hline & \multirow{2}{*}{ DuipGM } & 0.046 & & -0.283 & & & \\
\hline & & $(0.14)$ & & $(-0.59)$ & & & \\
\hline \multirow{6}{*}{$\begin{array}{l}\text { Fama- } \\
\text { French }\end{array}$} & \multirow{2}{*}{$\mathbf{R M}$} & 0.867 & & 0.041 & & \multirow{6}{*}{$82 \%$} & \\
\hline & & (2.47) & ** & $(0.11)$ & & & \\
\hline & \multirow{2}{*}{ SMB } & -0.378 & & 0.121 & & & 66.294 \\
\hline & & $(-1.30)$ & & $(0.31)$ & & & {$[0.00]$} \\
\hline & \multirow{2}{*}{ HML } & -0.819 & & 1.029 & & & \\
\hline & & $(-2.66)$ & $* * *$ & $(4.62)$ & ${ }^{* * *}$ & & \\
\hline \multirow{2}{*}{ ССАРМ } & & -0.988 & & 0.802 & & \multirow{2}{*}{$84 \%$} & 704.903 \\
\hline & & $(-3.73)$ & ${ }^{* * *}$ & (3.74) & $* * *$ & & {$[0.00]$} \\
\hline \multirow{6}{*}{$\begin{array}{c}\text { Extended } \\
\text { CCAPM }\end{array}$} & \multirow{2}{*}{ ND } & -0.005 & & 0.743 & \multirow[b]{2}{*}{ * } & \multirow{6}{*}{$98 \%$} & \\
\hline & & $(-0.12)$ & & (1.68) & & & \\
\hline & D & -0.135 & & 2.294 & & & 1048.259 \\
\hline & & $(-1.25)$ & & $(2.96)$ & ${ }^{* * *}$ & & {$[0.00]$} \\
\hline & \multirow{2}{*}{$\mathbf{R M}$} & 0.907 & & -0.007 & & & \\
\hline & & $(2.58)$ & ** & $(-0.53)$ & & & \\
\hline
\end{tabular}

1999:01 - 2008:02

\begin{tabular}{|c|c|c|c|c|c|}
\hline$\mu$ & \multicolumn{3}{|c|}{ b } & $\mathbf{R}^{2}$ & $\mathbf{J}_{T}$-Test \\
\hline 1.451 & \multicolumn{3}{|c|}{-0.401} & \multirow{2}{*}{$-27 \%$} & 54.210 \\
\hline$(2.51)$ & $* *$ & $(-2.72)$ & $* * *$ & & {$[0.00]$} \\
\hline 1.084 & \multirow{4}{*}{$* *$} & -1.192 & & \multirow{4}{*}{$70 \%$} & \multirow{4}{*}{$\begin{array}{r}146.878 \\
{[0.00]}\end{array}$} \\
\hline (2.09) & & $(-1.64)$ & & & \\
\hline 0.102 & & -0.005 & & & \\
\hline$(0.25)$ & & $(-0.04)$ & & & \\
\hline-0.014 & \multirow{8}{*}{$* * *$} & 0.568 & & \multirow{8}{*}{$92 \%$} & \multirow{8}{*}{$\begin{array}{r}73.295 \\
{[0.00]}\end{array}$} \\
\hline$(-0.03)$ & & $(0.65)$ & & & \\
\hline 0.275 & & -0.230 & & & \\
\hline (1.04) & & $(-0.20)$ & & & \\
\hline-0.719 & & 2.438 & & & \\
\hline$(-2.76)$ & & (1.23) & & & \\
\hline 0.052 & & -1.032 & & & \\
\hline$(0.16)$ & & $(-0.57)$ & & & \\
\hline 0.718 & & -0.465 & & \multirow{6}{*}{$54 \%$} & \multirow{6}{*}{$\begin{array}{r}51.100 \\
{[0.00]}\end{array}$} \\
\hline (1.36) & & $(-1.52)$ & & & \\
\hline 0.833 & \multirow{3}{*}{ ** } & -0.283 & & & \\
\hline$(2.39)$ & & $(-0.95)$ & & & \\
\hline 1.388 & & -0.705 & \multirow[b]{2}{*}{$* * *$} & & \\
\hline (2.32) & ${ }^{* *}$ & $(-2.85)$ & & & \\
\hline-1.062 & & 0.594 & & \multirow{2}{*}{$65 \%$} & 296.659 \\
\hline$(-3.53)$ & ${ }^{* * *}$ & $(2.94)$ & *** & & {$[0.00]$} \\
\hline 0.203 & & -0.271 & & \multirow{6}{*}{$97 \%$} & \multirow{6}{*}{$\begin{array}{r}1101.042 \\
{[0.00]}\end{array}$} \\
\hline (5.47) & ${ }^{* * *}$ & $(-2.08)$ & ** & & \\
\hline 0.146 & \multirow{4}{*}{ * } & 2.380 & & & \\
\hline (1.93) & & $(4.86)$ & *** & & \\
\hline 0.147 & & 0.003 & & & \\
\hline$(0.36)$ & & $(0.52)$ & & & \\
\hline
\end{tabular}

This table reports the results of the first-stage GMM approach for the two specified sub-periods. We construct an SDF $m_{t}$ and use the following moment conditions: $E\left(y_{t}^{e i} m_{t}\right)=0$ (where $y_{t}^{e i}$ is the excess return on the FX portfolios constructed through the procedure described in section 2.1 and $m_{t}=1-\left(f_{t}-\mu\right)^{\prime} b$, with $E\left(f_{t}\right)=\mu$. We estimate parameters $\mu$ and $b$. The $J_{T}$-test checks the validity of the model. The CAPM considers the world excess return as the only risk factor. The second model takes world excess return and M1 as the sources of risk. The International CAPM introduces the currency risk to the classic CAPM. The Fama-French model assumes that there are three risk factors: US market excess return, SMB, and HML (in this order). The CCAPM has the growth rate of real per capita consumption of nondurables as the only risk premium. The Extended CCAPM takes into consideration, besides the CCAPM factor, the growth rate of real per capita net stock of durables, and the US market excess return. $T$ stats are between round brackets (one, two or three asterisks denote significance levels of $10 \%, 5 \%$ and $1 \%$, respectively), while $p$-values for the $J_{T}$-test are between square brackets. 
Figure 3.1. Durable and Nondurable Consumption

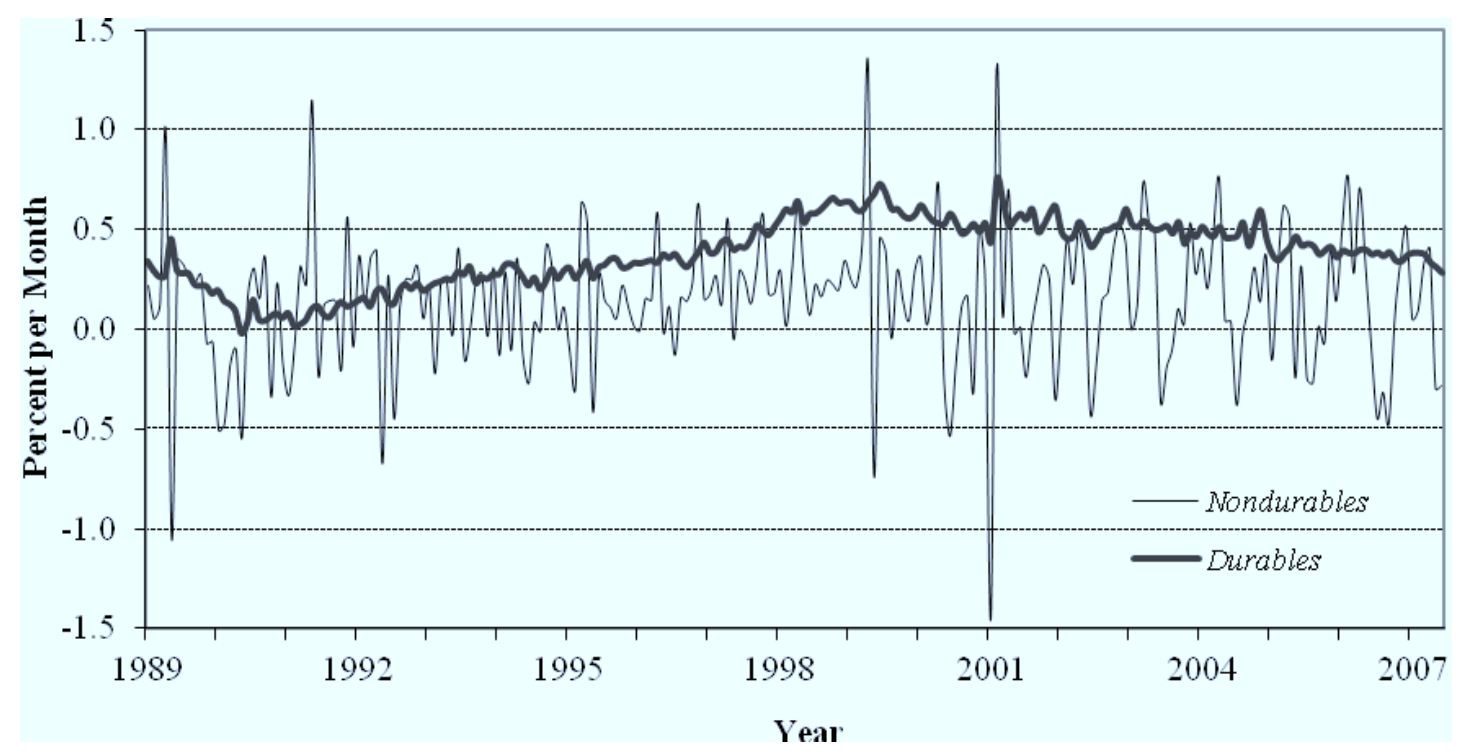

This figure reports the evolution in time, from 1989:09 to 2008:02, for the growth rate of real per capita consumption of nondurables, and for the growth rate of real per capita net stock of durables. 
Figure 3.2. Mean Estimated Returns vs. Mean Realized Returns for the FX

Portfolios Obtained through GMM First Stage Approach
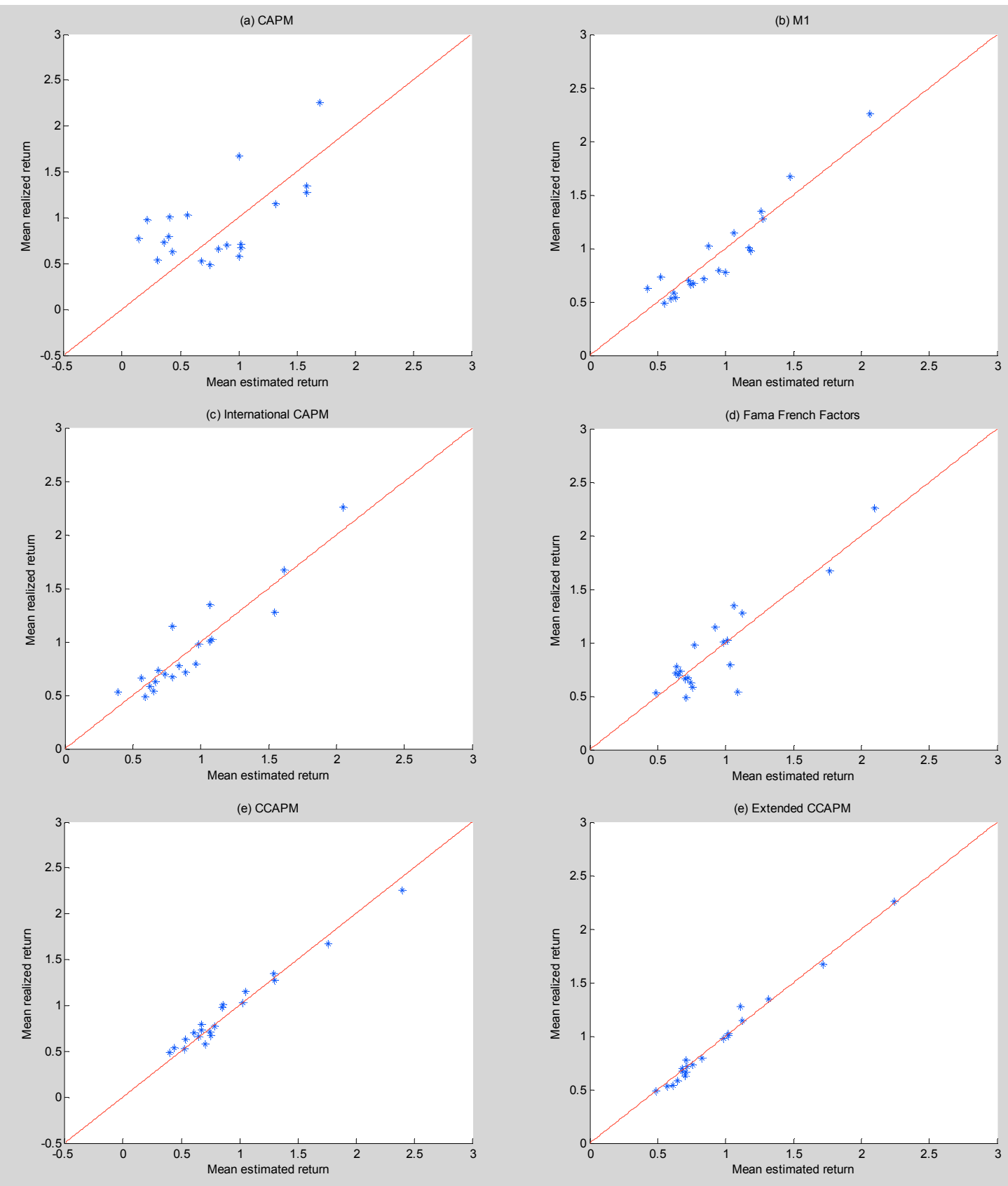

Based on the GMM first-stage procedure, we compute the mean estimated returns for the FX portfolios, constructed as described in section 2.1. The relationship between these averages and their corresponding realized averages are represented by the blue stars. The red line is the $45^{\circ}$ line. Each panel shows a different asset pricing model, as described in Section 3. 
Figure 3.3. Mean Estimated Returns vs. Mean Realized Returns for the FX Portfolios Obtained through GMM Second Stage Approach
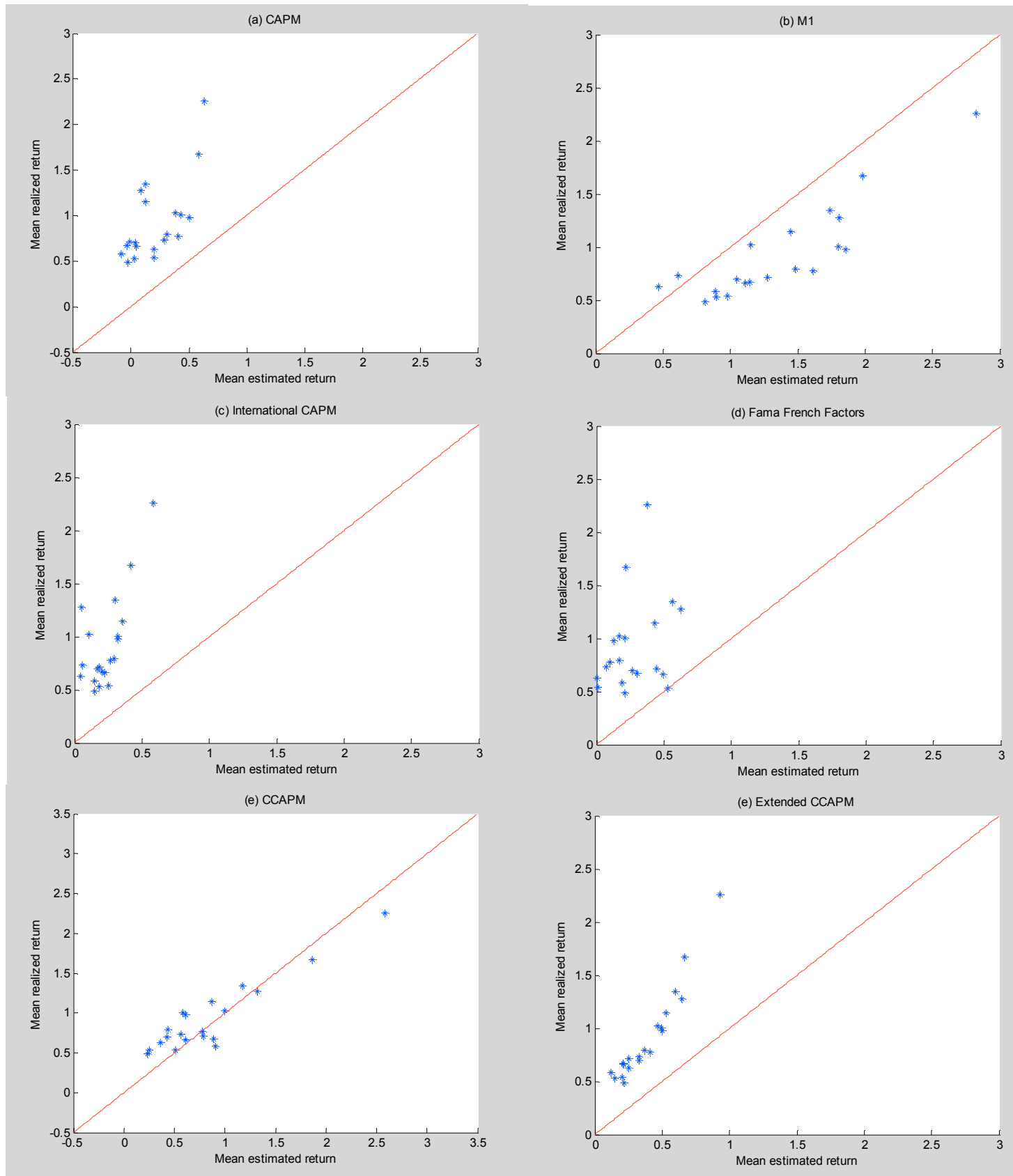

Based on the GMM second-stage procedure, we compute the mean estimated returns for the FX portfolios, constructed as described in section 2.1. The relationship between these averages and their corresponding realized averages are represented by the blue stars. The red line is the $45^{0}$ line. Each panel shows a different asset pricing model, as described in Section 3. 


\section{Figure 3.4. Mean Estimated Returns vs. Mean Realized Returns for the}

\section{FX Portfolios and the 25 Fama-French Portfolios}
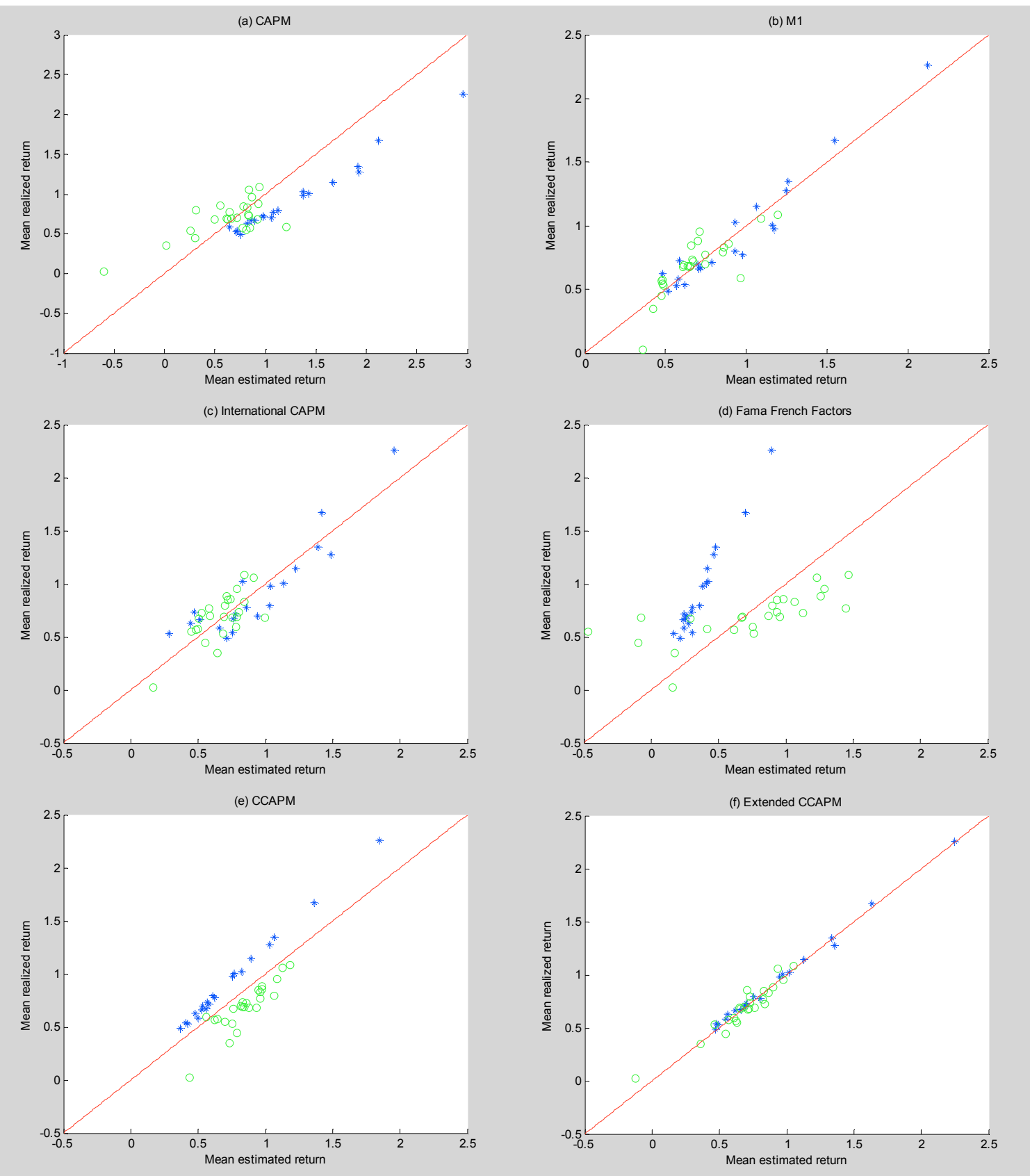

Based on the GMM first-stage procedure, we compute the mean estimated returns for the FX portfolios constructed as described in section 2.1 and the mean estimated returns on the 25 Fama-French portfolios, sorted by size and value. The relationship between the FX estimated averages and their corresponding realized averages are represented by the blue stars. We also graph the relationship between the mean estimated returns on the 25 Fama-French portfolios and their corresponding realized averages, as green circles. The red line is the $45^{0}$ line. Each panel shows a different asset pricing model, as described in Section 3. 


\section{Chapter 4: Currency Risk Premia and Uncovered Interest Parity in the International CAPM}

\section{Introduction}

Deviations from purchasing power parity (PPP) are common, sizable, and driven largely by nominal exchange rate movements. The implication is that investment opportunities depend on the country of residence: while nominal returns are identical for all investors, the purchasing power of the returns differs by country. In a mean-variance environment then the Sharpe-Lintner CAPM can no longer hold. A currency risk premium arises for each separate country (currency area) that constitutes a significant part of market demand, yielding the International CAPM of Solnik (1974a), Stulz (1981) and Adler and Dumas (1983).

Empirically, the International CAPM in its basic unconditional form does not contribute much to the Sharpe-Lintner CAPM. In particular, the currency risk premia are typically small and insignificant. Upon reflection this result is not surprising. Real currency risk is important, and increasingly so, for most corporations in today's global economy. Although Bartram, Brown, and Minton (2010) argue that much of the risk is hedged or passed through to consumers, remaining currency risk exposure is substantial. As a result, I expect currency risk loadings to be significant for most stocks. However, this does not imply that currency risk is priced.

The currency risk premium must be equal to the return on a zero-investment portfolio position perfectly correlated with real fluctuations in the currency value. If riskfree assets exist in each country the currency-premium-mimicking portfolio is simply an uncovered interest parity (UIP) position. Unconditionally and over longer time period 
UIP returns are small. It follows that the currency risk premia in the unconditional International CAPM are expected to be quantitatively negligible.

This paper uses results concerning persistent time variation in UIP returns to examine whether currency risk premia attain their theoretical importance once I condition on their levels expected from projected UIP returns. Whereas average UIP returns and hence currency risk premia may be negligible, the variances of expected UIP returns are conditionally sizable so that, combined with variations in currency risk loadings across assets, the currency risk can explain large differences in conditional expected returns.

I test the International CAPM and my conjecture regarding its failure in an unconditional setting by using a Generalized Method of Moments (GMM) technique that allows me to condition the currency risk premia on expected UIP returns. The data are the monthly equity index returns from December 1978 through February 2008 for 18 developed markets obtained from MSCI, supplemented with forward and spot exchange rates taken from the Bank of International Settlements and Datastream. I find that conditioning on the expected UIP returns represents a significant improvement over both the Sharpe-Lintner CAPM and the unconditional International CAPM. The theoretical predictions hold and I can conclude that currency risk is an important source of variation in expected returns across countries.

The paper is organized as follows. The second section explains the contribution in the perspective of the existing literature. The third section presents the model and theoretical implications, while the fourth provides information about the data and summary statistics. Section five presents the empirical results, and section six concludes. 


\section{Related Literature}

The International CAPM developed by Solnik (1974a), Stulz (1981) and Adler and Dumas (1983) starts from the violation of the Purchasing Power Parity (PPP) both in the long and short run. Accordingly, the same asset might yield different returns for different investors in different countries. Besides market risk, the investors also bear a different type of risk: the exchange risk. The foreign exchange risk is simply the percentage difference between the forward and spot rates due to the fact that PPP deviations behave approximately like real exchange rates (Adler and Dumas, 1983). Consequently, the International CAPM requires that the forward rate is a biased predictor of the spot rate and that Uncovered Interest Parity (UIP) does not hold. In the literature the proxy used most frequently is the nominal difference between the logs of the forward and spot exchange rates. ${ }^{19}$ Inflation is disregarded since the currencies considered bear negligible inflation risks (Dumas and Solnik, 1995). The problem with this risk premium is that economically it is very close to zero in absolute value, even if statistically it is different from zero.

Empirical tests of the International CAPM turn out to be inconclusive. The empirical literature can be divided into three types of tests. The first considers the International CAPM as a Sharpe-Lintner CAPM in an international setting (i.e., it ignores currency risk and simply replaces national market returns with world market returns). Ferson and Harvey $(1991,1993)$ find that there exists time variation in both market risk premia and betas. Harvey (1991) concludes that time-varying covariances can explain some, but not all of the cross-sectional variation in country returns. The unexplained variation may be due to model misspecification, imperfect markets integration, or other

\footnotetext{
${ }^{19}$ For a still relevant survey see Adler and Dumas (1983).
} 
sources of risk. Hence this literature suggests possible additional risk factors aside from market risk. Furthermore, De Santis and Gerard (1997) test the conditional market CAPM in an international setting and they conclude that other forms of risk besides market risk exist and that currency risk is priced in addition to the market.

The second branch of the literature tests the unconditional version of the International CAPM as developed by Solnik (1974a), Stulz (1981) and Adler and Dumas (1983). Stehle (1977) uses a two-pass approach to test the two CAPM versions (SharpeLintner and International) and concludes that the intercepts are considerably higher than the models predict. However, he also finds that the signs of the coefficients are as predicted by the International CAPM. Similar inconclusive results are obtained in other studies (Solnik, 1974b, and Korajczyk and Viallet, 1989).

The third approach is considered in more recent studies based on a conditional version of the International CAPM. The basic idea behind the conditional version is that investors base their portfolio allocations on information known in the market. These papers consider two different econometrical procedures: GARCH and GMM. De Santis and Gerard (1998), Engel and Rodrigues (1989), Chan et al. (1992), and Ng (2004) use GARCH/ARCH specifications and find mixed results on the validity of the International CAPM. GMM is used by Dumas and Solnik (1995). When testing the unconditional version, they cannot reject the Sharpe-Lintner CAPM and reject the International CAPM. The conditional version provides the opposite result: the Sharpe-Lintner CAPM is rejected, while the International CAPM cannot be rejected.

The recent paper of Francis, Hasan, and Hunter (2008) is an example of the third approach. It is most similar to my approach in that it allows for time variation in the 
currency risk premia. However, the conditioning variables are of a different nature in that they are country-specific variables such as U.S. imports or exports as a share of GDP, and the model is difficult to relate to the International CAPM in that value and size factors are added and the exchange factors are U.S.-specific weighted exchange indices.

As discussed, the currency risk premia in the International CAPM can be mimicked by the returns on UIP positions, which are very small in absolute value. If one could predict the deviations from UIP and, say, take only the time periods in which they are large in absolute value, the empirical application of the International CAPM for these periods should generate significant currency risk premia.

Fortunately, a large literature exists which examines deviations from UIP and studies the predictability of these deviations. Recent papers in this literature include Chabout and Wright (2005), Chinn and Meredith (2002), Mark and Wu (1998), Okunev and White (2003), Serban (2010), Spagnolo et al. (2005), and Villanueva (2007).

This paper uses the procedure derived in the first essay as the method of predicting UIP deviations and employs the predicted returns on the UIP portfolio positions as the conditioning variables for testing the International CAPM. This paper thus considers a new conditional setting for the International CAPM. Hansen's (1982) GMM allows me to test unconditional implications of this conditional model and provides the natural econometric method for testing my specification.

\section{The model}

Differences arise in investment opportunities for investors residing in different countries due to the failure of purchasing power parity to hold in each period. In an otherwise 
perfect CAPM world the International CAPM of Adler and Dumas (1983) then holds in which currency risk, for each country other than the benchmark, supplements world market risk. The stochastic discount factor for the International CAPM, assuming linearity and allowing for time variation, is

$M_{t}=1-\lambda_{t-1}^{0}-\sum_{i=1}^{L} \lambda_{t-1}^{i} r_{t}^{n+1}-\lambda_{t-1}^{m} r_{t}^{m}$

where $m$ is the number of assets consisting of $n$ national equity portfolios, $L$ currency positions and 1 world market portfolio. There are $L+1$ countries ( $L$ foreign countries plus 1 home country). The $r_{t}^{j}$ for $j=1 \ldots n$ represent excess returns for country-specific equity portfolios in the home country currency net of the risk free return of the home country. The $r_{t}^{j}$ for $j=n+1 \ldots n+L$, represent the currency factor realizations: the zero-investment returns of the positions based on borrowing one unit in the domestic currency to purchase a riskless asset denominated in one of $L$ foreign currencies (i.e., the UIP deviations), and $r_{t}^{j}$, for $j=m$ is the excess return of the world market portfolio in the home country currency. The $\lambda_{t-1}^{i}$ represent $L+1$ time-varying prices of risk plus a constant. The constant is set to normalize:

$-\lambda_{t-1}^{0}=\sum_{i=1}^{L} \lambda_{t-1}^{i} E_{t-1}\left(r_{t}^{n+1}\right)+\lambda_{t-1}^{m} E_{t-1}\left(r_{t}^{m}\right) \Rightarrow E_{t-1}\left(M_{t}\right)=1$,

Absence of arbitrage opportunities implies that all zero-investment positions are priced consistent with the stochastic discount factor so that

$E_{t-1}\left(M_{t} r_{t}^{j}\right)=0, j=1 \ldots m$, 
Using equations (4.1), (4.2), and (4.3) I obtain the International CAPM of Adler and Dumas (1983) with the additional feature that the prices of covariance risk may be time varying:

$$
E_{t-1}\left(r_{t}^{j}\right)=\sum_{i=1}^{L} \lambda_{t-1}^{i} \operatorname{cov}\left(r_{t}^{j}, r_{t}^{n+i}\right)+\lambda_{t-1}^{m} \operatorname{cov}\left(r_{t}^{j}, r_{t}^{m}\right), \quad j=1 \ldots m .
$$

In the following I thus take the covariances to be constant but the prices of risk are allowed to vary over time. Note that the constant $\lambda_{t}^{0}$ does not show up in equation (4.4) and merely served for normalization purposes.

The traditional CAPM ignores the $\lambda^{i}$ for $i=1 \ldots L$, the world prices of exchange rate covariance risk, focusing only on the world price of market covariance risk, $\lambda^{m}$. This may be appropriate only for explaining unconditional expected returns. The reason is that the terms $\lambda_{t-1}^{i}$, reflecting the net returns from a zero-investment position in currency $i$, are very small on average over the long run due to small unconditional UIP deviations. As a result, even if currency risk is important and the $\lambda_{t-1}^{i}$ are conditionally sizable, an unconditional version of the International CAPM may show that currency risk is not priced. However, it is well known that UIP deviations are predictable. Conditioning the International CAPM on the expected values of the deviations from UIP should lead to significant currency risk premia and proper evaluation of the International CAPM.

A large literature considers UIP deviations and predictions based on mean reversion and moving average or momentum formulations. ${ }^{20}$ I use here the specification

20 See for instance Chabout and Wright (2005), Chinn and Meredith (2002), Froot and Frankel (1989), Mark and Wu (1998), Spagnolo et al. (2005), and Villanueva (2007). 
in chapter 2, which combines both types of formulations. Thus, I can obtain the expected values of the deviations from UIP $\left(y_{t}^{i}\right)$ by using the following model:

$y_{t}^{i}=-\left(1-\delta^{i}\right)\left(x_{t-1}^{i}-\mu^{i}\right)+\sum_{j=1}^{J} \rho_{j}^{i}\left(x_{t-j}^{i}-x_{t-j-1}^{i}\right)+\varepsilon_{t}^{i}$,

where $x_{t}^{i} \equiv \sum_{s=0}^{t} y_{s}^{i}$ represents the cumulative past excess returns from UIP deviations which equals the deviation from purchasing power parity.

At $t-1$, I have the information $Z_{t-1}^{i}=E_{t-1}\left(y_{t}^{i}\right)$ for all currencies $i$. The International CAPM in this context can be written conditional on information set $Z_{t} \equiv\left\{Z_{t}^{i}\right\}_{i=n+1}^{m}$ as:

$$
\begin{gathered}
E\left(r_{t}^{j} \mid Z_{t-1}\right)=\sum_{i=1}^{L} \lambda_{t-1}^{i} \operatorname{cov}\left(r_{t}^{j}, r_{t}^{n+i}\right)+\lambda_{t-1}^{m} \operatorname{cov}\left(r_{t}^{j}, r_{t}^{m}\right), j=1 \ldots m, \\
\text { with } \lambda_{t-1}^{i}=Z_{t-1}^{i} b^{i}, \quad i=1 \ldots L, \text { and } \lambda_{t-1}^{m}=b^{m}
\end{gathered}
$$

Equation (4.6) reflects the assumption that time variation in the prices of risk is proportional to the information set $Z_{t}$. If I set $Z_{t}=\mathbf{1}_{L}$ for all $t$ (where $1_{L}$ represents an Lvector of ones) I obtain the unconditional version of the International CAPM, with the coefficients to be estimated, $b=\left(b_{1}, \ldots b_{m}\right)$, representing the $L+1$ unconditional prices of covariance risk.

I implement the Generalized Method of Moments (GMM) developed by Hansen (1982) in combination with the stochastic discount factor approach. Define innovation vector $\varepsilon_{t}=\left(\varepsilon_{t}^{1}, \varepsilon_{t}^{2}, \ldots . \varepsilon_{t}^{m}\right)$ with

$\varepsilon_{t}^{j}=r_{t}^{j}-r_{t}^{j}\left(\sum_{i=1}^{L} \lambda_{t-1}^{i}\left[r_{t}^{n+i}-E\left(r_{t}^{n+i}\right)\right]+\lambda_{t-1}^{m}\left[r_{t}^{m}-E\left(r_{t}^{m}\right)\right]\right)$, 
Implying from equations $(4.1)-(4.3)$ that $E\left(\varepsilon_{t}\right)=0$. This provides the moment conditions. Define $\varepsilon$ as the $T \times m$ matrix of the $\varepsilon_{t}^{j}$. Equation (4.8) states that there are $m$ moment conditions:

$\mathbf{1}_{T}^{\prime} \varepsilon / T=0$

The parameters to estimate are $b^{i}$ with $i=1 \ldots \mathrm{L}$ and $b^{m}$. There are thus $L+1$ parameters to estimate. To test the model I need overidentification of the parameters. In other words, I need $m>L+1$ so that I need at least one more test assets than countries.

The appropriate test statistic to test the null hypothesis of validity of the model follows a $\chi^{2}$ distribution with the number of degrees of freedom equal to the difference between the number of moment conditions and the number of parameters to be estimated (i.e., the number of overidentifying restrictions gives the number of degrees of freedom). Consequently, the number of degrees of freedom in this case is equal to $m-(L+1)$.

To obtain the risk premia from the prices of risk I convert from the stochastic discount factor formulation to the beta format:

$E\left(r_{t}^{j} \mid Z_{t-1}\right)=\sum_{i=1}^{L} \gamma_{t-1}^{i} \beta^{i j}+\gamma_{t-1}^{m} \beta^{m j}, \quad j=1 \ldots m$,

where the $\gamma_{t}^{i}$ are the conditional risk premia and the $\beta^{i j}$ are the factor loadings of asset $j$ to factor $i$. Each $\beta^{i j}$ can be obtained as an element of the $m x(L+1)$ matrix

$\boldsymbol{\beta}=\left[\operatorname{cov}\left(\mathrm{r}^{\mathrm{j}}, \mathrm{r}^{\mathrm{i}}\right)\right] \mathbf{V}_{\mathbf{f}}^{-\mathbf{1}}$,

and the risk premia $\gamma_{t}^{i}$ as the $(L+1)$-vector

$\gamma=\mathbf{V}_{\mathrm{f}} \lambda$ 
obtained from the $(L+1)$-vector of conditional prices of risk $\lambda_{t}^{i}$, with $\mathbf{V}_{\mathbf{f}}$ the variancecovariance matrix of the $L+1$ risk factors.

\section{The data and summary statistics}

\subsection{Data and the Currency Return Measures}

The data consist of two sets. The first set includes the 1-month forward and spot exchange rates taken from the Bank of International Settlements and Datastream. ${ }^{21} \mathrm{I}$ obtain monthly data for the German mark/ euro, UK pound and Japanese yen. The home currency is the US dollar. The deviations from UIP are computed as the log differences between the forward and spot exchange rates. I use December 1978 through February 2008 as the time period. The start of the sample is determined by the availability of the forward and spot exchange rates from BIS.

The second data set is the MSCI database. The papers focuses on the standard 18 developed countries: Australia, Austria, Belgium, Canada, Denmark, France, Germany, Hong Kong, Italy, Japan, the Netherlands, Norway, Singapore, Spain, Sweden, Switzerland, the United Kingdom and the USA. As the market return, I consider the MSCI World index returns. The home-currency risk free rate is subtracted from the home-currency return of each index to generate the excess returns. The risk free rate is the one-month U.S. Treasury bill rate (from Ibbotson Associates), obtained from Kenneth French's website.

\footnotetext{
${ }^{21}$ Due to availability, the data are taken from two sources: for the period December 1978 - December 2001 from the BIS dataset, and for January 2002 - February 2008 from Datastream.
} 


\subsection{Currency Returns and Risk Premia}

The zero-investment return from an uncovered interest position in the risk free asset of country $k$ is my currency return $r_{t}^{n+k}$ :

$r_{t}^{n+k}=\left(1+i_{t-1}^{k}\right)\left(\frac{e_{t}^{k}}{e_{t-1}^{k}}\right)-\left(1+i_{t-1}^{0}\right)$,

where subscript $t$ reflects the time period in which the return is known. The exchange rate $e_{t}^{k}$ is stated in the home currency per unit of country $k$ currency. The risk free rate of country $k$ prevailing at time $t$ is given as $i_{t-1}^{k}$ and superscript 0 marks the home country.

Covered interest parity implies:

$$
\left(1+i_{t-1}^{k}\right)\left(\frac{f_{t-1}^{k}}{e_{t-1}^{k}}\right)=\left(1+i_{t-1}^{0}\right),
$$

with $f_{t-1}^{k}$ the forward rate at time $t-1$ measured as units of home currency per country $k$ currency to be delivered at time $t$. Substitute equation (4.13) into (4.12) to eliminate $\left(1+i_{t-1}^{k}\right) / e_{t-1}^{k}:$

$\frac{r_{t}^{n+k}}{1+i_{t-1}^{0}}=\frac{e_{t}^{k}-f_{t-1}^{k}}{f_{t-1}^{k}}$

Ignoring second-order terms, equation (4.14) implies a good approximation for currency returns as

$r_{t}^{n+k}=\ln \left(e_{t}^{k}\right)-\ln \left(f_{t-1}^{k}\right)$

The currency return has two key features: (1) it is a tradable zero-investment return, meaning that investors can actually obtain this return in the market; (2) it is conditionally (that is, conditional on information available at $t-1$ ) perfectly correlated with the value of 
country $k$ currency. As a result, the conditional currency risk premium must be $E_{t-1}\left(r_{t}^{n+k}\right):^{.22}$

$E_{t-1}\left(r_{t}^{n+k}\right)=E_{t-1}\left[\ln \left(e_{t}^{k}\right)\right]-\ln \left(f_{t-1}^{k}\right)$,

A positive (conditional) currency risk premium occurs when the expected spot rate exceeds the forward rate and is called "normal backwardation" in the forward market. A negative (conditional) currency risk premium is called "contango." In the "normal" case the premium for taking on exchange rate risk is positive. However, there is no expectation that currency risk premia should be positive because one could symmetrically consider the country $k$ investor's perspective. Her UIP position would generate a currency return of $\ln \left(1 / e_{t}^{k}\right)-\ln \left(1 / f_{t-1}^{k}\right)=-r_{t}^{n+k}$. Hence, the currency risk premium from the foreign investor's perspective is the negative of that of the home investor.

The sign of the risk premium is determined by the currency value's covariance with the stochastic discount factor and cannot be established without a full general equilibrium model. Unfortunately, the theoretical International CAPM literature such as Adler and Dumas (1983) has not been cast in a full general equilibrium context. Intuitively, one would expect the country $k$ currency risk premium to be positive for a home country that has relatively large wealth so that its currency risk preferences prevail.

The instrumental variables I employ empirically, $Z_{t-1}^{k}=E_{t-1}\left(y_{t}^{k}\right)$, with $y_{t}^{k}$

given in equation (4.5) represent the conditionally expected currency returns so I have

\footnotetext{
${ }^{22}$ Note that the rate of home currency appreciation $\ln \left(e_{t}^{k}\right)-\ln \left(e_{t-1}^{k}\right)$ cannot be generated as an excess return in the market since it excludes the opportunity cost of borrowing the funds in the home currency. If the risk free rate is subtracted the resulting return can be generated in the market but is dominated by the UIP position (in equilibrium the difference in return would be an unobservable convenience yield that someone holding foreign currency for transactions or precautionary purposes would obtain).
} 
$Z_{t-1}^{k}=E_{t-1}\left(y_{t}^{k}\right)=E_{t-1}\left(r_{t}^{n+k}\right)$

\subsection{Descriptive Statistics}

Table 4.1 presents descriptive statistics for the 22 returns series considered: 18 national equity returns, 1 world market return and 3 foreign currency returns. As expected from the literature (Burnside, 2008; Burnside et al., 2010; Dumas and Solnik, 1995; De Santis and Gerard, 1998), the mean excess returns for equity are higher in absolute value than the mean excess returns in the foreign exchange markets. The standard deviations are also larger for the former.

\subsection{Two-Pass Approach}

Firstly, I implement the two-pass approach for the classic CAPM and the Conditional and Unconditional International CAPM. The beta version is provided in equation (4.9). The dependent variables are the excess returns of the 18 national equities. The first regressor is the excess world market return, while the other three regressors represent the currency risk premia for the three currencies considered in this paper. The classic CAPM assumes that PPP holds, which leads to: $\beta^{i j}=0$.

I use the two-pass approach as proposed by Fama-MacBeth (1973), but simplified as in Cochrane (2005). The first pass computes $\beta^{j}$ for each of the independent variables by using a time-series approach for each $j$. The second pass considers a cross-sectional regression for each moment in time and uses the $\beta^{j}$ estimated in the first stage. The results are presented in Table 4.2. I find statistically insignificant intercepts for the first pass for both classic and International CAPM, according to the GRS test. The $\mathrm{R}^{2}$ for second pass 
regressions are $-17 \%$ and $28 \%$ respectively. Note the negative $\mathrm{R}^{2}$ for the CAPM, due to the omission of the constant in the second pass. However, the CAPM gives a statistically significant coefficient, while for the International CAPM only one of the estimated risk premia is different from zero apart from the market risk premium, raising doubts on whether currency risk is priced. ${ }^{23}$

Table 4.2 also presents results for a two-pass approach for the conditional International CAPM. Given its conditional nature, it is difficult to implement in the simple framework provided in equation (4.9). I compute the risk premia by using formula (4.11), taking into consideration that my $Z_{t-1}$ is the conditional part of the currency price of risk. The procedure follows then as described in Cochrane (2005). Besides the first coefficient, the rest are statistically different from zero, showing an improvement compared to the unconditional version of the International CAPM. The $\mathrm{R}^{2}$ also shows an improvement, increasing to $37 \%$.

The two-pass approach cannot give us a few very interesting insights on, for instance, if the model considered are valid or not. The GMM estimation that follows can help us in this regard.

\section{GMM Estimation of the Conditional Model}

The empirical approach follows Dumas and Solnik (1995) with the critical difference that the conditioning variables are not obtained as a set of variables with demonstrated general forecast power for stock returns, but rather directly as a variable shown to be an appropriate instrument for the currency risk premia.

\footnotetext{
${ }^{23}$ I do not report the Shanken corrected errors, because I find the Shanken correction factor very close to 1, such that it does not affect the results significantly.
} 


\subsection{Estimation of the Classic and International CAPM's}

Panels A and B of Table 4.3 report the results for the GMM estimation for the International and Sharpe-Lintner CAPM. If the instrumental variable, $Z$, is set equal to 1 , I obtain the unconditional results for the two asset pricing models. The null hypothesis for the overidentifying restrictions can be tested by using a $J_{T}$ test. This test computes the minimized value of the objective function and, multiplied by the number of observations, follows a $\chi^{2}$ distribution. I present the $\chi^{2}$ statistic and its $\mathrm{p}$-value in Table 4.3. The null hypothesis cannot be rejected at the $1 \%$ and $5 \%$ level for the ICAPM, but is rejected at the $10 \%$ significance levels, while the CAPM is rejected at the 5\% level. My results are somewhat similar to the Dumas and Solnik (1995) results, even with a different sample period and them considering only four national equity returns. ${ }^{24}$ They obtain a bit lower p-value of 0.049 for the International CAPM and a bit higher p-value for the CAPM (they cannot reject the validity of the Sharpe-Lintner CAPM).

For comparison, consider that De Santis and Gerard (1998), using a GARCH specification, obtain for the International CAPM the following coefficients (i.e., prices of risk): 2.79 for the world market factor, -1.87 for the German mark, 1.92 for the Japanese yen and -0.05 for the British pound. None of these coefficients are statistically different from zero. The magnitudes differ from those in my paper (not surprisingly given the different time period considered and the differences in methodology).

\footnotetext{
${ }^{24}$ As in Dumas and Solnik (1995) I obtain $\lambda_{\mathrm{m}}$ greater than 1 in both cases (International and Sharpe-Lintner CAPM). Adler and Dumas (1983) argue that $\lambda_{\mathrm{m}}$ represents the world coefficient of risk aversion because it is defined as the weighted average of the coefficients of risk aversion of all national investors. I obtain coefficients of 1.84 and 2.09 for the Sharpe-Lintner and International CAPM respectively, suggesting that the coefficient of risk aversion is greater than 1 .
} 
Panel $\mathrm{C}$ presents the test of the main hypothesis. When conditioning on the expected deviations from UIP, the International CAPM is no longer rejected (a p-value of 0.93 for the $\chi^{2}$ statistic). ${ }^{25}$ This result suggests strongly that currency risk premia are important. Currency risk is important only when the expected returns from uncovered interest arbitrage are sufficiently large.

\subsection{The Risk Premia}

Equation (4.11) shows how I can infer the estimated risk premia. Table 4.4 exhibits the results. The market risk premium but also each of the currency risk premia are statistically significant and bear the expected signs.

\section{Conclusions}

The International CAPM is a very attractive model. It can be derived from a utility-maximizing framework and it has a solid theoretic background. However, the empirical results are its biggest enemy, as is the case for the Sharpe-Lintner CAPM. A currency risk should be priced, but the UIP deviations are very small compared to returns obtained on the stock market.

This paper argues that this is the only problem of the International CAPM. If one uses the information that predict the currency risk premia, then the International CAPM is

${ }^{25}$ Given that the number of observations is the same in both conditional and unconditional models, one might wonder why the minimized objection function is so much smaller for the unconditional version. When using an OLS estimator, that would mean a larger pricing error in my model. However, that is not the case for the GMM. Cochrane (2005, p. 216) gives the following equation for $J_{T}: J_{T}=g_{T}^{\prime} S^{-1} g_{T}$, where $g_{T}$ are the pricing errors and $S$ is a spectral density matrix. For any GMM estimation, the $S$ matrix changes and this might increase or decrease $J_{T}$ without giving me an idea of what happens with the pricing errors. He concludes that the $J_{T}$ statistic should not be used to compare the success of new model with other similar models. 
not rejected. While the inconclusive results for the International CAPM in its unconditional form hold in this sample as well, I show that conditioning on the expected deviations from UIP leads to a definite acceptance of the International CAPM.

The following issues are worth considering: (1) nest my model with that of Dumas and Solnik (1995) to see if my conditional factor drives out theirs; (2) include more currency returns and see to which extent there is segmentation in that equity returns are explained differently from currency returns; (3) use additional moment conditions based on managing the basis assets to see how well our conditional International CAPM explains momentum and mean reversion returns in FOREX; (4) examine the quantitative importance of the currency risk premia for explaining differences in mean returns; (5) take more seriously the fact that the instrumental variables should be interpreted as currency risk premia. This means that the prices of risk should be multiplied, not by $\mathrm{Z}$ but by the inverse factor covariance matrix times Z; (6) allow deviations from $E_{t-1}\left(M_{t}\right)=1$ so that pricing errors may have non-zero means; (7) consider one-stage GMM to check for robustness. 
Table 4.1

\section{Summary Statistics}

\begin{tabular}{lcc}
\hline & Mean & $\begin{array}{c}\text { Standard } \\
\text { Deviation }\end{array}$ \\
\hline Australia & 0.586 & 6.863 \\
Austria & 0.401 & 6.310 \\
Belgium & 0.627 & 5.567 \\
Canada & 0.510 & 5.677 \\
Denmark & 0.688 & 5.367 \\
France & 0.533 & 6.156 \\
Germany & 0.412 & 6.309 \\
Hong Kong & 0.742 & 8.981 \\
Italy & 0.533 & 6.930 \\
Japan & 0.146 & 6.364 \\
Netherlands & 0.696 & 5.216 \\
Norway & 0.707 & 7.645 \\
Singapore & 0.340 & 7.629 \\
Spain & 0.703 & 6.418 \\
Sweden & 0.861 & 7.018 \\
Switzerland & 0.510 & 5.091 \\
United Kingdom & 0.556 & 5.247 \\
USA & 0.503 & 4.267 \\
\hline World & 0.445 & 4.102 \\
\hline Duip of JY & 0.126 & 2.872 \\
Duip of BP & -0.147 & 2.537 \\
Duip of GM & 0.037 & 2.677 \\
\hline
\end{tabular}

This table reports summary statistics for the variables used in the empirical study: monthly returns averages and standard deviations. $1 \%$ is reported in the table as 1 . The equity returns refer to the MSCI index computed from the MSCI database, minus the one-month Treasury bill rate (from Ibbotson Associates). The deviations from UIP for German mark/ euro (GM), British pound (BP) and Japanese yen (JY) relative to the US dollar are computed as (the log of) the forward premium. The data are taken from Bank of International Settlements and Datastream. The sample period is 1979:01 - 2008:02. 
Table 4.2

Two-Pass Approach

\begin{tabular}{|c|c|c|c|c|c|}
\hline & Japanese Yen & British Pound & $\begin{array}{c}\text { German } \\
\text { Mark/Euro }\end{array}$ & Market & $\mathrm{R}^{2}$ \\
\hline \multicolumn{6}{|c|}{ CAPM } \\
\hline $\begin{array}{l}\text { Coefficient } \\
\text { t-stat }\end{array}$ & & & & $\begin{array}{c}0.510 \\
(7.53)^{* * *}\end{array}$ & $-17 \%$ \\
\hline \multicolumn{6}{|c|}{ International CAPM } \\
\hline $\begin{array}{l}\text { Coefficient } \\
\text { t-stat }\end{array}$ & $\begin{array}{c}0.707 \\
(2.00)^{* *}\end{array}$ & $\begin{array}{r}-0.062 \\
(-0.13) \\
\end{array}$ & $\begin{array}{r}-0.070 \\
(-0.17) \\
\end{array}$ & $\begin{array}{c}0.426 \\
(5.79)^{* * *}\end{array}$ & $28 \%$ \\
\hline \multicolumn{6}{|c|}{ Conditional International CAPM } \\
\hline $\begin{array}{l}\text { Coefficient } \\
\text { t-stat }\end{array}$ & $\begin{array}{l}-1.412 \\
(-1.35)\end{array}$ & $\begin{array}{c}-2.105 \\
(-3.10)^{* * *}\end{array}$ & $\begin{array}{c}-1.189 \\
(-2.52)^{* *}\end{array}$ & $\begin{array}{c}0.402 \\
(5.63)^{* * *}\end{array}$ & $37 \%$ \\
\hline
\end{tabular}

The equity excess returns (including the world market excess returns) are monthly index returns in dollar terms obtained from MSCI net of the one-month Treasury bill rate (from Ibbotson Associates). The deviations from UIP for the German Mark/Euro (GM), UK Pound (BP) and Japanese Yen (JY) relative to the US Dollar are computed as (the log of) the forward premium. These data are from the Bank of International Settlements and Datastream. The sample period is 1989:08 - 2008:02. This table reports the results for the second pass in the two pass approach for the three analyzed models: CAPM, International CAPM and my conditional version of the International CAPM. The first pass contains a series of time series regressions for each equity excess return on the factors predicted by the model. The second pass regresses cross-sectionally the averages of the equity excess returns on the betas found in the first pass. The numbers between round brackets represent t-statistics and the stars represent the significance level $\left(^{*}\right.$ is $10 \%$; ** is $5 \% ; * * *$ is $1 \%$ level of significance). 


\section{Table 4.3}

GMM Results

\section{Panel A. International CAPM}

\begin{tabular}{|c|c|c|c|c|c|}
\hline & & Coefficient & t-Statistic & $J_{T}$-test & p-value \\
\hline$b_{1}$ & Japanese Yen & 5.353 & 1.590 & 27.809 & 0.065 \\
\hline$b_{2}$ & $\begin{array}{l}\text { British } \\
\text { Pound }\end{array}$ & 0.321 & 0.064 & & \\
\hline$b_{3}$ & $\begin{array}{c}\text { German } \\
\text { Mark/Euro }\end{array}$ & -5.323 & -1.092 & & \\
\hline$b_{m}$ & Market & 2.092 & 1.122 & & \\
\hline
\end{tabular}

Panel B. CAPM

\begin{tabular}{cccccc}
\hline & & Coefficient & t-Statistic & $\boldsymbol{J}_{\boldsymbol{T}}$-test & p-value \\
\hline$b_{m}$ & Market & 1.845 & 1.059 & 33.624 & 0.040 \\
\hline
\end{tabular}

Panel C. Conditional International CAPM

\begin{tabular}{|c|c|c|c|c|c|}
\hline & & Coefficient & t-Statistic & $J_{T}$-test & p-value \\
\hline$b_{1}$ & Japanese Yen & -5.173 & -0.954 & 10.058 & 0.930 \\
\hline$b_{2}$ & $\begin{array}{l}\text { British } \\
\text { Pound }\end{array}$ & -7.370 & -0.690 & & \\
\hline$b_{3}$ & $\begin{array}{c}\text { German } \\
\text { Mark/Euro }\end{array}$ & -10.313 & -0.784 & & \\
\hline$b_{m}$ & Market & 1.544 & 0.7867 & & \\
\hline
\end{tabular}

This table reports the results for: International CAPM (Panel A), Sharpe-Lintner (Panel B) and the Conditional International CAPM(Panel C). The estimation method used is GMM and the analyzed equation

$$
\begin{aligned}
& E\left(r_{t}^{j} \mid Z_{t-1}\right)=\sum_{i=1}^{L} \lambda_{t-1}^{i} \operatorname{cov}\left(r_{t}^{j}, r_{t}^{n+i}\right)+\lambda_{t-1}^{m} \operatorname{cov}\left(r_{t}^{j}, r_{t}^{m}\right), j=1 \ldots m \\
& \lambda_{t-1}^{i}=Z_{t-1}^{i} b^{i}, \quad i=1 \ldots L, \text { and } \lambda_{t-1}^{m}=b^{m} .
\end{aligned}
$$

$Z_{t-1}$ is set to 1 in the unconditional versions and the $\lambda^{i}$,s are assumed zero in the CAPM. The $\lambda$ 's are prices of risk. The $J_{T}$-test follows a $\chi^{2}$ distribution with [ $(\mathrm{N}+1)$ minus the number of estimated parameters] degrees of freedom. The null hypothesis: model is valid. In italics: the p-values for the $J_{T}$-test. 
Table 4.4

Estimated Risk Premia for the Conditional International CAPM

\begin{tabular}{lrr}
\hline & \multicolumn{1}{c}{ Mean } & \multicolumn{1}{c}{ St error } \\
\hline Market & 0.238 & 0.0007 \\
JY & -0.095 & 0.0084 \\
BP & -0.018 & 0.0070 \\
GM & -0.028 & 0.0043 \\
\hline
\end{tabular}

This table reports the estimated risk premia for the conditional International CAPM, computed as:

$\boldsymbol{\gamma}=\mathbf{V}_{\mathbf{f}} \boldsymbol{\lambda}$ where $\boldsymbol{\lambda}$ is the vector of conditional prices of risk for the $\mathrm{L}+1$ factors and $\mathbf{V}_{\mathbf{f}}$ is the matrix of variance-covariance for the conditional risk factors. The units are percent per month. 


\section{Chapter 5: Conclusions}

The present dissertation thesis centers on the foreign exchange and equity markets, around their similarities and differences. The ideas presented in these three essays are novel and can represent a very important contribution to the existing literature.

The first essay describes two of the most important financial markets and how they are more interconnected than initially believed. Even though the momentum and mean reversion phenomena were found in both markets, nobody thought about looking more into this issue. My first essay finds that a strategy of combining mean reversion and momentum in the FX markets, a strategy similar to one implemented before in the equity market by Balvers and $\mathrm{Wu}$ (2006), can give important abnormal returns. The existence of both momentum (not only moving average rules, on which the current literature focuses when dealing with this phenomenon) and mean reversion (towards the mean return, not towards PPP, as in the current literature) is documented in Figure 2.1. The momentum effect is stronger in the FX market than the stock market, but the mean reversion half life is the same (i.e., 45 months). Table 2.4 presents how similar the two markets really are in terms of the evolution over different combinations $(K, J)$. Even though in terms of average annual returns the stock markets dominate the FX market, the Sharpe ratios tell a completely different picture. In this essay, I also compare the results for this strategy with other strategies implemented in the FX market, such as carry trades, and I find that usually the Sharpe ratios are higher in Table 2.4 than in the existing literature.

The similarities between the two markets lead to one of two conclusions: (1) a common source of risk exists, leading the positive abnormal returns in both markets; (2) the two markets are both inefficient. The second essay (written with Rudolf F. Klein) tries to find if risk factors are responsible for the profitability of the above mentioned strategy. We consider a multitude of asset pricing models considered in both the equity and FX markets literature. The first approach, time series, cannot find any conclusive models that fit the data. The second approach is the two-pass regression analysis as described in Cochrane (2005). One of the models, Yogo's (2006) version of the extended

CCAPM seems a better fit than the other models with a higher $\mathrm{R}^{2}$, but the results are still inconclusive. The third and last method is the GMM approach. As Cochrane (2005) 
notices, one should only look at the first stage GMM in order to find the statistical and economical intuition of the results. Table 3.4 shows that by far the CCAPM and Extended CCAPM do a better job in explaining the abnormal returns than any of the other analyzed models. Figure 3.3 also shows a better fit especially for the classic CCAPM. Table 3.5 provides a model comparison and, even after adding the 25 Fama-French portfolios as dependent variables, the extended CCAPM is a very good fit with an $\mathrm{R}^{2}$ of $97 \%$ (see Figure 3.4). Even though we could add some more asset pricing models into the analysis (such as those used in the hedge funds literature), we believe that this is the most comprehensive paper on this issue and we conclude that Yogo's (2006) Extended CCAPM is the best fit for explaining FX market abnormal returns (results in line with the highly controversial paper by Lustig and Verdelhan, 2007).

The third essay again considers the abnormal returns found in chapter 2, but this time as a window to predict the currency risk premia as specified by the International CAPM developed by Solnik (1974a), Stulz (1981) and Adler and Dumas (1983). The above mentioned model is very intuitive, but does not verify empirically. I implement a procedure similar to Dumas and Solnik (1995), who consider a conditional version of the International CAPM and show it to be valid by using a GMM approach. However, I condition the International CAPM on the predicted values of the currency risk premia, hence arguing that the model is only rejected due to very low (in absolute value) proxies for the foreign risk. Even though the two pass approach provided in Table 4.2 is not necessarily strong enough in showing a significant improvement between the conditional and unconditional versions of the International CAPM, the GMM approach shows a much cleared picture in Table 4.3. The only model not rejected is indeed my version of the International CAPM. I also estimate the new currency risk premia and find them statistically different from zero (which was not the case for the unconditional International CAPM). I conclude that our version of the International CAPM is the best in explaining the abnormal returns found in the international equity markets. There are a few concerns about the power of the tests in this last essay. The future direction of the essay is more thoroughly described in its last section. 


\section{References}

Adler, M., Dumas, B., 1983. International portfolio choice and corporation finance: A synthesis. The Journal of Finance 38, 925-984.

Arellano, M., Bond, S., 1991. Some Tests of Specification for Panel Data: Monte Carlo Evidence and an Application to Employment Equations. The Review of Economic Studies 58, 277-297.

Baba, N., Packer, F., 2009. Interpreting deviations from covered interest parity during the financial turmoil of 2007-08. Journal of Banking and Finance 33, 1953-1962.

Balvers, R., Wu, Y., 2006. Momentum and mean reversion across national equity markets. Journal of Empirical Finance 13, 24-48.

Balvers, R., Wu, Y., Gilliland, E., 2000. Mean reversion across national stock markets and parametric contrarian investment strategies. Journal of Finance 55, 745-772.

Bartram, S., Brown, G., Minton, B., 2010. Resolving the exposure puzzle: The many facets of exchange rate exposure. Journal of Financial Economics 95, 148-173.

Breeden, D., 1979. An intertemporal asset pricing model with stochastic consumption and investment opportunities. Journal of Financial Economics 7, 265-96.

Burnside, A., 2007. The cross-section of foreign currency risk premia and consumption growth risk: A comment. NBER Working Paper No. W13129.

Burnside, A., 2009. Comment on "Carry Trades and Currency Crashes". In: Acemoglu D., Rogoff, K., Woodford, M. NBER Macroeconomics Annual 2008. NBER Books, University of Chicago Press.

Burnside, A., Eichenbaum, M., Kleshchelski, I., Rebelo, S., 2010. Do peso problems explain the returns to the carry trade? NBER Working Papers 14054.

Chabout, A., Wright, J., 2005. Uncovered interest parity: It works, but not for long. Journal of International Economics 66, 349-362.

Chan, K., Hameed, A., Tong, W., 2000. Profitability of momentum strategies in the international equity markets. Journal of Financial and Quantitative Analysis 35, 153-172.

Chan, K., Karolyi, G., Stulz, R., 1992. Global financial markets and the risk premium on U.S. equity. Journal of Financial Economics 32, 137-167.

Chiang, T., Jiang, C., 1995. Foreign exchange returns over short and long horizons. International Review of Economics \& Finance 4, 267-282. 
Chinn, M., Meredith, G., 2002. Testing uncovered interest parity at short and long horizons during the post-Bretton Woods era. NBER Working Paper No 11077.

Cochrane, J., 2005. Asset pricing. Princeton University Press: Princeton, NJ.

De Bondt, W., Thaler, R., 1985. Does the stock market overreact? The Journal of Finance 40, 793-805.

De Santis, R., Fornari, F., 2008. Does business cycle risk account for systematic returns from currency positioning? The international perspective. Available at SSRN: http://ssrn.com/abstract=1140663.

De Santis, G., Gerard, B., 1997. International asset pricing and portfolio diversification with time-varying risk. The Journal of Finance 52, 1881-1912.

De Santis, G., Gerard, B., 1998. How big is the premium for currency risk? Journal of Financial Economics 49, 375-412.

Deutsche Bank, 2007. Currencies: Value investing. Deutsche Bank: London.

Dornbusch, R., 1976. Expectations and exchange rate dynamics. Journal of Political Economy 84, 1161-1176.

Dumas, B., Solnik, B., 1995. The world price of foreign exchange risk. The Journal of Finance 50, 445-479.

Engel, C., 1996. The forward discount anomaly and the risk premium: A survey of recent evidence, Journal of Empirical Finance 3, 123-192.

Engel, C., Hamilton, J., 1990. Long swings in the dollar: Are they in the data and do markets know it? The American Economic Review 80, 689-713.

Engel, C., Rodrigues, A., 1989. Tests of International CAPM with time-varying covariances. Journal of Applied Econometrics 4, 119-138.

Engel, C., West, K.D., 2005. Exchange rates and fundamentals. Journal of Political Economy 113, 485-517.

Fama, E., 1984. Forward and spot exchange rates. Journal of Monetary Economics 14, 319-338.

Fama, E., Blume, M., 1966. Filter rules and stock market trading profits. Journal of Business 39, 226-241.

Fama, E., French, K., 1988. Permanent and temporary components of stock prices. The Journal of Political Economy 96, 246-273. 
Fama, E., French, K., 1993. Common risk factors in the returns on stocks and bonds. Journal of Financial Economics 33, 3-56.

Fama, E., MacBeth, J., 1973. Risk, return, and equilibrium: Empirical tests. The Journal of Political Economy 81, 607-636.

Ferson, W., Harvey, C., 1991. The variation of economic risk premiums. Journal of Political Economy 99, 385-415.

Ferson, W., Harvey, C., 1993. The risk and predictability of international equity returns. The Review of Financial Studies 6, 527-566.

Fillat, J., Garduno, H., 2005. GMM Estimation of an Asset Pricing Model with Habit Persistence", Working Paper, University of Chicago.

Fong, W., 2010. A stochastic dominance analysis of yen carry trades. Journal of Banking and Finance 34, 1237-1246.

Francis, B., Hasan, I, Hunter, D., 2008. Can hedging tell the full story? Reconciling differences in United States aggregate- and industry-level exchange rate risk premium. Journal of Financial Economics 90, 169-196.

Friesen, G., Weller, P., Dunham, L., 2009. Price trends and patterns in technical analysis: A theoretical and empirical examination. Journal of Banking and Finance 33, 10891100.

Froot, K., Frankel, J., 1989. Forward discount bias: Is it an exchange risk premium? The Quarterly Journal of Economics 104, 139-161.

Hansen, L., 1982. Large sample properties of generalized method of moments estimators. Econometrica 50, 1029-1054.

Harris, R., Yilmaz, F., 2009. A momentum trading strategy based on the low frequency component of the exchange rate. Journal of Banking and Finance 33, 1575-1585.

Harvey, C., 1991. The world price of covariance risk. The Journal of Finance 46, 111157.

Hodrick, R., 1989. Risk, uncertainty and exchange rates. Journal of Monetary Economics $23,433-459$.

Hodrick, R., Srivastava, S., 1986. The covariation of risk premiums and expected future spot rates. Journal of International Money and Finance 5, 5-21 (supplement). 
Hollifield, B., Yaron, A., 2003. The foreign exchange risk premium: Real and nominal factors. No. 2001-E13, GSIA Working Papers, Carnegie Mellon University, Tepper School of Business.

Imbens, G. W., 2002. Generalized Method of Moments and Empirical Likelihood. Journal of Business \& Economic Statistics 20, 493-506.

Jegadeesh, N., Titman, S., 1993. Returns to buying winners and selling losers: Implications for stock market efficiency. The Journal of Finance 48, 65-91.

Korajczyk, R., Viallet, C., 1989. An empirical investigation of international asset pricing. Review of Financial Studies 2, 553-585.

LeBaron, B., 1999. Technical trading rule profitability and foreign exchange intervention. Journal of International Economics 49, 125-214.

Lewellen, J., Nagel, S., Shanken, J., 2010. A skeptical appraisal of asset pricing tests. Journal of Financial Economics 96, 175-194.

Lintner, J., 1965. The valuation of risk assets and the selection of risky investments in stock portfolios and capital budgets. The Review of Economics and Statistics 47, 13-37.

Lucas, R., Jr., 1978. Asset prices in an exchange economy. Econometrica 46, 1429-45.

Lustig, H., Verdelhan, A., 2007. The cross section of foreign currency risk premia and consumption growth risk. American Economic Review 97, 89-117.

Mark, N., 1985. On time varying risk premia in the foreign exchange market: An econometric analysis. Journal of Monetary Economics 16, 3-18.

Meese, R., Rogoff, K., 1983. Empirical exchange rate models of the seventies: Do they fit out of sample? Journal of International Economics 14, 3-24.

Mussa, M., 1979. Empirical regularities in the behavior of exchange rates and teories of the foreign exchange market. Carnegie-Rochester Conference Series on Public Policy, Elsevier 11, 9-57.

Neely, C., 2002. The temporal pattern of trading rule returns and Central Bank intervention: Intervention does not generate technical trading rule profits. Journal of International Economics 58, 211-232.

Newey, W., West, K., 1987. A simple positive definite, heteroscedasticity and autocorrelation consistent matrix. Econometrica 55, 703-705. 
Ng, D., 2004. The International CAPM when expected returns are time-varying. Journal of International Money and Finance 23, 189-230.

Okunev, J., White, D., 2003. Do momentum-based strategies still work in foreign currency markets? Journal of Financial and Quantitative Analysis 38, 425-447.

Rogoff, K., 1996. The purchasing power parity puzzle. Journal of Economic Literature 34, 647-668.

Ross, S., 1976. The arbitrage theory of capital asset pricing. Journal of Economic Theory $13,341-360$.

Rubio, G., Lozano, M., 2010. Evaluating alternative methods for testing asset pricing models with historical data. Journal of Empirical Finance, Forthcoming. Available at SSRN: http://ssrn.com/abstract=1629905

Sharpe, W., 1964. Capital asset prices: A theory of market equilibrium under conditions of risk. The Journal of Finance 19, 425-442.

Solnik, B., 1974a. An equilibrium model of the international capital market. Journal of Economic Theory 8, 500-524.

Solnik, B., 1974b.The international pricing of risk: An empirical investigation of the world capital market structure. Journal of Finance 29, 365-378.

Spagnolo, F., Psaradakis, Z., Sola, M., 2005. Testing the unbiased forward exchange rate hypothesis using a Markov switching model and instrumental variables. Journal of Applied Econometrics 20, 423-437.

Stehle, R., 1977. An empirical test of the alternative hypotheses of national and international pricing of risky assets. The Journal of Finance 32, 493-502.

Stulz, R., 1981. A model of international asset pricing. Journal of Financial Economics 9, 383-406.

Summers, L., 1986. Does the stock market rationally reflect fundamental values? The Journal of Finance 41, 591-601.

Sweeney, R., 1986. Beating the foreign exchange market. The Journal of Finance 41, 163-182.

Szakmary, A., Mathur, I., 1997. Central Bank intervention and trading rule profits in foreign exchange markets. Journal of International Money and Finance 16, 513-535.

Taylor, M. P., 1987. Covered interest parity: A high-frequency, high-quality data study. Economica 54, 429-438. 
Villanueva, O., 2007. Forecasting currency excess returns: Can the forward bias be exploited? Journal of Financial and Quantitative Analysis 42, 963-990.

Yogo, M., 2006. A consumption-based explanation of expected stock returns. Journal of Finance, 61, 539-580. 


\section{ALINA F. KLEIN}

Lynchburg College

School of Business \& Economics

1501 Lakeside Drive

Lynchburg, VA 25401
E-mail: klein.a@lynchburg.edu

Home Phone: (434) $321-4773$

Office Phone: (434) $544-8794$

http://sites.google.com/site/alinafserban/

\section{Education:}

Ph. D. in Economics West Virginia University, Morgantown, WV, 2010

B. S. in Economics Academy of Economic Studies, Bucharest, Romania, 2003

\section{Areas of Interest:}

Research: Asset Pricing, International Finance

Teaching: Economics, Finance

Published Papers:

"Combining Mean Reversion and Momentum Trading Strategies in Foreign Exchange Markets", published under maiden name: Alina F. Serban, Journal of Banking \& Finance, Volume 34, Issue 11, November 2010, p. 2720-2727

\section{Working Papers:}

“Are FX trading returns compensation for risk?” (with Rudolf F. Klein)

"Currency Risk Premia and Uncovered Interest Parity in the International CAPM" (with Ronald J. Balvers)

\section{Academic Positions:}

2010 - present: Assistant Professor of Economics, Lynchburg College

2005 - 2010: Graduate Teaching Assistant, West Virginia University

\section{Memberships and Awards:}

$2010 \quad$ : Midwest Finance Association graduate student travel grant

2009 : Kaiser Best Doctoral Student Award, West Virginia University

2009 : Southern Economic Association Doctoral Student Award

2009 : Member, Financial Management Association

2000 - 2003: Merit-based Scholarship at the Academy of Economic Studies, Bucharest 


\section{Conference Participations:}

2010: Presentation at the FMA Conference - New York, NY, October 20-23

2010: Presentation, discussion and session chair at the MFA Conference - Las Vegas, NV, February 24-27

2009: Presentation at the SEA Annual Meeting - San Antonio, TX, November 21-23

2002: Presentation at the Annual Session of Academic Research, the International Finance section, Bucharest

2000: Presentation at the Annual Session of Academic Research, the Global Economy section, Bucharest

Other Professional Experience:

Referee:

Journal of Banking \& Finance

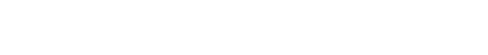

